\title{
Selection of rhizobacteria for pre-emergence control of wild poinsettia, horseweed and sourgrass
}

\author{
Seleção de rizobactérias para o controle em pré-emergência de leiteiro, \\ buva e capim-amargoso
}

\section{Cleiton Burnier de OLIVEIRA ${ }^{1 ; 2}$; Bruno Sérgio VIEIRA ${ }^{3}$; Gustavo Mendes ESPÍNDOLA ${ }^{4}$; Carine Resende CARDOSO ${ }^{5}$}

\begin{abstract}
${ }^{1}$ Parte da dissertação de mestrado do primeiro autor
${ }^{2}$ Mestre em Produção Vegetal. Instituto Federal do Triângulo Mineiro/Uberaba. Av. Doutor Randolfo Borges Júnior, 2900 Bairro: Univerdecidade - CEP: 38064-300 - Uberaba/MG. Rodovia MG-230 - km 8. Rio Paranaíba-MG, Brasil. CEP: $38810-$ 000, Caixa Postal 22. cleiton@labfarroupilha.com

${ }^{3}$ Engenheiro Agrônomo, Doutor em Fitopatologia. Instituto de Ciências Agrárias, Universidade Federal de Uberlândia, Campus Monte Carmelo, Rodovia LMG 746, Km01, s/n, Bloco 1. Monte Carmelo-MG, Brasil. CEP: 38500-000. brunovieira@ufu.br (autor para correspondência).

${ }^{4}$ Engenheiro Agrônomo. Instituto de Ciências Agrárias, Universidade Federal de Uberlândia, Campus Monte Carmelo, Rodovia LMG 746, Km01, s/n, Bloco 1. Monte Carmelo-MG, Brasil. CEP: 38500-000. gustavoagromc@gmail.com

${ }^{5}$ Engenheira Agrônoma, Doutora em Fitopatologia. Syngenta. carine@grupofarroupilha.com
\end{abstract}

\section{Recebido em: 22-02-2019; Aceito em: 21-05-2019}

\begin{abstract}
This study aimed to select rhizobacteria isolates for pre-emergence control of three glyphosate-resistant species: horseweed (Conyza sumatrensis), sourgrass (Digitaria insularis), and wild poinsettia (Euphorbia heterophylla). Nineteen strains of Bacillus spp. and thirty-four strains of Pseudomonas spp. were isolated from soil samples from the states of Minas Gerais, São Paulo, Paraná, and Santa Catarina. These strains were evaluated in vitro and under greenhouse conditions for inhibition of seed germination and growth of target weeds. Several strains of Bacillus spp. and Pseudomonas spp. inhibited the germination and radicle growth of the three target species in Petri dishes containing agar-water medium with the respective bacterial isolates, separately. However, Bacillus spp. strains A1B1, A1B3, A1B4, A2B2, A2B3, A10B1, A10B5, A11B1, and A13B3 were the only ones to inhibit germination of horseweed seeds in greenhouse soil. The soil methodology (greenhouse) was more effective in the selection of strains than the in vitro methodology for not overestimating the bacterium-host interaction and for simulating better field conditions. Promising Bacillus spp. strains must be identified at the species level and characterized for metabolite production, plant growth regulation, root colonization, and effect on cultivated plants.
\end{abstract}

Additional keywords: Biological control; Conyza sumatrensis; Digitaria insularis; Euphorbia heterophylla.

\section{Resumo}

O objetivo deste trabalho foi selecionar isolados de rizobactérias para o controle em pré-emergência de três espécies que apresentam resistência ao glyphosate: buva (Conyza sumatrensis), capim-amargoso (Digitaria insularis) e leiteiro (Euphorbia heterophylla). Foram isolados 19 estirpes de Bacillus spp. e 34 de Pseudomonas spp. de amostras de solos de localidades, nos Estados de Minas Gerais, São Paulo, Paraná e Santa Catarina, e avaliados quanto à inibição da germinação de sementes e ao crescimento das plantas daninhas-alvo in vitro e em casa de vegetação. Vários isolados de Bacillus spp. e Pseudomonas spp. inibiram a germinação e o crescimento de radículas das três espécies-alvo em placas de Petri contendo o meio constituído por ágar-água com os respectivos isolados bacterianos, separadamente; contudo, somente os isolados de Bacillus spp. A1B1, A1B3, A1B4, A2B2, A2B3, A10B1, A10B5 A11B1 e A13B3 inibiram a germinação das sementes de buva em solo, em casa de vegetação. A metodologia em solo (casa de vegetação) foi mais eficaz para a seleção dos isolados do que a metodologia in vitro por não superestimar a interação entre a bactéria e o hospedeiro, e por simular melhores condições de campo. Os isolados de Bacillus spp. promissores deverão ser identificados a nível de espécie, caracterizados quanto à produção de metabólitos, reguladores de crescimento de plantas, colonização de radicular e efeito em plantas cultivadas.

Palavras-chave adicionais: Controle biológico; Conyza sumatrensis; Digitaria insularis; Euphorbia heterophylla. 


\section{Introduction}

Weeds represent one of the main limiting factors for agricultural productivity worldwide due to their multiple deleterious effect on crops, crop interference, contamination of the product harvested with seeds and other plant parts, and increased moisture content of the product harvested, hindering its processing, preservation, and consequently reducing its value (Oliveira et al., 2011).

Chemical weed control is currently the most used method, given its low cost and high agronomic efficiency (Oliveira et al., 2011). The glyphosate molecule is the most widely used for this purpose and the adoption of crops resistant to this herbicide along with the end of its patent life in the year 2000, favored its wide acceptability and use (Duke \& Powles, 2008). However, continuous use of this herbicide resulted in the selection of resistant weed biotypes in Brazil, such as horseweed (Conyza sumatrensis (Retz. E.Walker), ryegrass (Lolium multiflorum Lam.), sourgrass (Digitaria insularis (L.) Mez. ex. Ekman), windmill grass (Chloris polydactyla (L.) Sw.) (Barroso \& Toledo, 2014 I, II, and III; Christoffoleti \& Nicolai, 2016), and wild poinsettia (Euphorbia heterophylla L.) (Prigol et al., 2014).

Therefore, it is necessary new methods for controlling these species. Among the most attractive possibilities is the biological control, which consists in the suppression or stabilization of weed populations at subeconomic levels using natural enemies (FloresVargas \& O'Hara, 2006).

Biological control based on the use of deleterious bacteria in plants, known as Deleterious Rhizobacteria (DRB), has been studied to aid weed management (Kennedy et al., 2001; Patil, 2014).

The rapid growth of bacterial isolates and, consequently, their greater facility for large-scale production can potentially make DRBs outstand fungi as bioherbicides ( $\mathrm{Li}$ et al., 2003). In addition, nonphytopathogenic bacteria have been known to reduce seed germination, inhibit seedling growth, and decrease root growth and elongation by producing phytotoxins and plant regulators such as indole-3-acetic acid (IAA) (Kennedy et al., 2001).

The selection of rhizobacteria that can inhibit germination and/or plant growth has a relevant advantage due to the low possibility of resistance development (Flores-Vargas \& O'Hara, 2006), further contributing with the environment and providing sustainable weed management.

Thus, this study selected rhizobacteria isolates for pre-emergence control of horseweed (Conyza sumatrensis), sourgrass (Digitaria insularis), and wild poinsettia (Euphorbia heterophylla). These species are considered of great importance for the Brazilian agriculture with reported cases of resistance to glyphosate and other herbicide molecules such as ALS and Protox inhibitors (Trezzi et al., 2006; Santos et al., 2014).

\section{Materials and methods}

\section{Isolation of rhizobacteria from soil: Bacillus spp. and Pseudomonas spp.}

Bacterial strains were isolated from 20 soil samples collected in different landscapes in four Brazilian states, as shown in Table 1. The sampling criterion chosen for the study was random sampling in agricultural production areas and native forests (Table 1). Approximately 100 grams of soil were collected in the $0-10 \mathrm{~cm}$ soil layer in each sampled site, being then placed in paper bags, stored in a thermal box, and sent to the laboratory for the isolation of rhizobacteria.

From the samples collected, specific laboratory methods were used to isolate bacteria from the genera Bacillus and Pseudomonas. The isolation of bacteria belonging to the genus Bacillus followed the methodology described by the World Organization (1985). To that end, one gram of soil was diluted in $10 \mathrm{~mL}$ of sterile saline solution $\left(0.01 \mathrm{mM} \mathrm{CaCO}_{3} 7 \mathrm{H}_{2} \mathrm{O}\right.$; $0.08 \mathrm{mM} \mathrm{MgSO} 4.7 \mathrm{H}_{2} \mathrm{O} ; 0.006 \mathrm{mM} \mathrm{FeSO}_{4} .7 \mathrm{H}_{2} \mathrm{O} ; 0.07$ $\mathrm{mM} \mathrm{MnSO} 4.7 \mathrm{H}_{2} \mathrm{O} ; 0.006 \mathrm{mM} \mathrm{ZnSO}_{4} .7 \mathrm{H}_{2} \mathrm{O} ; \mathrm{pH} 7.0$ ) in a $15 \mathrm{~mL}$ microtube, being then homogenized in vortex for one minute. Subsequently, a $1 \mathrm{~mL}$ aliquot was removed for pasteurization $\left(12\right.$ minutes at $80^{\circ} \mathrm{C}$ in a water bath - microprocessor controlled model Q215M QUIMIS $^{\circledR}$, and subsequent thermal shock on crushed ice for 5 minutes), aiming at the selection of sporulating bacteria. Thereafter, the suspension was diluted four times, reaching a concentration of $10^{-4}$. Then, $100 \mu \mathrm{L}$ of the suspension was applied in a Petri dish with Tryptone Soybean Agar (TSA) medium, followed by incubation in a BOD chamber at $28{ }^{\circ} \mathrm{C}$ for 24 hours (Alfenas \& Mafia, 2007). Colonies were individualized by morphological characteristics and maintained in Petri dishes containing the same medium mentioned above.

For the isolation of Pseudomonas, $10 \mathrm{~g}$ of soil from each sample was added in a $250 \mathrm{~mL}$ Erlenmeyer flask with $95 \mathrm{~mL}$ of sterile phosphate buffered saline (PBS, $10 \mathrm{mM} \mathrm{K}_{2} \mathrm{PO}_{4}-\mathrm{KH}_{2} \mathrm{PO}_{4}, 0.14 \mathrm{M} \mathrm{NaCl}$; $\mathrm{pH}$ 7.2), being stirred for $30 \mathrm{~min}$ at $200 \mathrm{rpm}$ on a rotary shaker. Thereafter, $10^{-1}$ of the suspension was diluted in PBS and plated on King's B agar medium (King et al., 1954) supplemented with $75 \mathrm{mg} \mathrm{L}^{-1}$ cycloheximide to prevent fungal contamination, and with $75 \mathrm{mg} \mathrm{L}^{-1}$ penicillin and $45 \mathrm{mg} \mathrm{L}^{-1}$ novobiocin to prevent the growth of other bacteria. The plates were incubated at $28^{\circ} \mathrm{C}$ for three days. The representative colonies were selected and pricked out through King's B agar streaks to obtain pure colonies (Tuite, 1969). Fluorescent pigment production was detected by exposing bacterial colonies to ultraviolet light $(<260 \mathrm{~nm}$ wavelength). The isolates obtained were kept at $4{ }^{\circ} \mathrm{C}$ in a refrigerator, being preserved by the mineral oil conservation technique (Alfenas \& Mafia, 2007). 
Table 1 - Description of soil samples collected for the rhizobacteria isolation to control of wild poinsettia (Euphorbia heterophylla), sourgrass (Digitaria insularis) and horseweed (Conyza sumatrensis) in pre-emergence.

\begin{tabular}{|c|c|c|c|c|c|c|c|c|}
\hline ID & City & State & Latitude (S) & Longitude (W) & Collection date & Landscape & $\mathrm{NBI}$ & NPI \\
\hline $\mathrm{A} 1$ & São João da Mata & Minas Gerais & $21^{\circ} 56^{\prime} 24^{\prime \prime}$ & $46^{\circ} 00^{\prime} 36^{\prime \prime}$ & 06/07/2016 & $\mathrm{NF}$ & 3 & 2 \\
\hline A2 & Palmeira & Paraná & $25^{\circ} 25^{\prime} 21.23^{\prime \prime}$ & $49^{\circ} 59^{\prime} 59.99 "$ & 06/15/2016 & Wheat & - & 2 \\
\hline A3 & Lagora Formosa & Minas Gerais & $18^{\circ} 53^{\prime} 50.759^{\prime \prime}$ & $46^{\circ} 31^{\prime} 46.92^{\prime \prime}$ & $10 / 18 / / 2016$ & Bean & - & 7 \\
\hline A4 & Alfredo Wagner & Santa Catarina & $27^{\circ} 41^{\prime} 19.28$ & $49^{\circ} 19^{\prime} 41^{\prime \prime} 53$ & 06/15//2016 & $\mathrm{NF}$ & 3 & 1 \\
\hline A5 & São Joaquim da Barra & São Paulo & $20^{\circ} 32.4^{\prime} 830^{\prime \prime}$ & $47^{\circ} 51.1^{\prime} 950 "$ & $10 / 20 / / 2016$ & Sugar cane & - & - \\
\hline A6 & Serra Negra & São Paulo & $22^{\circ} 35.08^{\prime} 50^{\prime \prime}$ & $46^{\circ} 47.2^{\prime} 16.0^{\prime \prime}$ & $10 / 20 / / 2016$ & Sugar cane & - & - \\
\hline A7 & Lagoa Formosa & Minas Gerais & 18ㄴ9'29.788" & $46^{\circ} 26^{\prime} 28.835^{\prime \prime}$ & $10 / 25 / / 2016$ & $\mathrm{NF}$ & - & 1 \\
\hline A8 & Bebedouro & São Paulo & $20^{\circ} 14^{\prime} 53.174 "$ & $49^{\circ} 17^{\prime} 50.701 "$ & 07/18//2016 & Citrus & - & 5 \\
\hline A9 & Bebedouro & São Paulo & $20^{\circ} 22^{\prime} 0.214^{\prime \prime}$ & $49^{\circ} 9^{\prime} 53.057^{\prime \prime}$ & 07/18//2016 & Citrus & 3 & 3 \\
\hline A10 & Icém & São Paulo & $21^{\circ} 3^{\prime} 27.436^{\prime \prime}$ & $48^{\circ} 28^{\prime} 16.669 "$ & 07/18//2016 & Sugar cane & 3 & 2 \\
\hline A11 & Angatuba & São Paulo & $23^{\circ} 30^{\prime} 37^{\prime \prime}$ & $48^{\circ} 34^{\prime} 32.75^{\prime \prime}$ & 07/20//2016 & Corn & - & 4 \\
\hline A12 & Patos de Minas & Minas Gerais & $18^{\circ} 31^{\prime} 02.0^{\prime \prime}$ & $46^{\circ} 26^{\prime} 18.8^{\prime \prime}$ & 09/27//2016 & $\mathrm{NF}$ & 3 & - \\
\hline A13 & Lagoa Formosa & Minas Gerais & $18^{\circ} 49^{\prime} 58.5^{\prime \prime}$ & $46^{\circ} 26^{\prime} 32.3^{\prime \prime}$ & $10 / 25 / / 2016$ & Coffee & - & 1 \\
\hline A14 & Coromandel & Minas Gerais & $18^{\circ} 28^{\prime} 51.182^{\prime \prime}$ & $46^{\circ} 58^{\prime 28.09 "}$ & 01/23//2017 & $\mathrm{NF}$ & - & 2 \\
\hline A15 & Coromandel & Minas Gerais & $18^{\circ} 30^{\prime} 33.052^{\prime \prime}$ & $46^{\circ} 57^{\prime} 27.846^{\prime \prime}$ & 01/23//2017 & $\mathrm{NF}$ & - & - \\
\hline A16 & Coromandel & Minas Gerais & $18^{\circ} 40^{\prime} 12.997^{\prime \prime}$ & $46^{\circ} 50^{\prime} 6.518^{\prime \prime}$ & 01/23//2017 & $\mathrm{NF}$ & - & 1 \\
\hline A17 & Coromandel & Minas Gerais & $18^{\circ} 39^{\prime} 1.832^{\prime \prime}$ & $46^{\circ} 42^{\prime} 2.484^{\prime \prime}$ & 01/23//2017 & $\mathrm{NF}$ & - & - \\
\hline A18 & Presidente Olegário & Minas Gerais & $18^{\circ} 31.2^{\prime} 63^{\prime \prime}$ & $45^{\circ} 97.4^{\prime} 15.1^{\prime \prime}$ & $01 / 24 / / 2017$ & $\mathrm{NF}$ & - & 1 \\
\hline A19 & Presidente Olegário & Minas Gerais & $18^{\circ} 33^{\prime} 39.3^{\prime \prime}$ & $46^{\circ} 01.0^{\prime} 32.4^{\prime \prime}$ & 01/25//2017 & NF & 3 & 1 \\
\hline A20 & João Pinheiro & Minas Gerais & $18^{\circ} 53.5^{\prime} 71.9^{\prime \prime}$ & 46¹5.6'29.4" & $01 / 24 / 2017$ & $\mathrm{NF}$ & - & - \\
\hline
\end{tabular}

ID: Soil sample identification; NF: Native forest; NBI: number of Bacillus spp. isolates; NPI: number of Pseudomonas spp isolates. 


\section{Evaluation of the in vitro antagonistic potential of rhizobacteria against target weeds}

Cultures of each Bacillus spp. strains were produced in liquid Luria-Bertani medium (Alfenas \& Mafia, 2007) at $25^{\circ} \mathrm{C}$ for five days, in the absence of light, in $250 \mathrm{~mL}$ Erlenmeyer flasks under static conditions (without agitation). The selected isolates of Pseudomonas spp. were fermented in half-strength King's B medium (half the nutrients per liter) at $29^{\circ} \mathrm{C}$, under $120 \mathrm{rpm}$ rotary shaking in $250 \mathrm{ml}$ Erlenmeyer flasks for 72 hours.

The concentration of bacterial strains was determined by the serial dilution technique in King's B medium for Pseudomonas spp. and TSA medium for Bacillus spp. Concentrations ranged from $10^{4}$ to

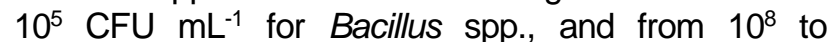
$10^{9} \mathrm{CFU} \mathrm{mL}^{-1}$ for Pseudomonas spp.

Weed seeds, purchased from the company Agro Cosmos - Pesquisa e Plantas Daninhas, Shokucho do Brasil Ltda., were surface sterilized by immersion in $1 \%$ sodium hypochlorite solution $(\mathrm{NaOCl})$ for three minutes. The seeds were then washed three times in sterile distilled water and transferred to sterile filter paper. A volume of $1 \mathrm{~mL}$ of bacterial suspension of each isolate was transferred to the surface of the agar-water medium in Petri dishes of $9 \mathrm{~cm}$ diameter and spread with the aid of a Drigalski loop. Fifteen seeds of each weed species were placed separately in each Petri dish and incubated in BOD chamber, as shown in Table 2. The control consisted of adding 1 $\mathrm{mL}$ of sterile water per Petri dish, followed by the distribution of 15 seeds of each weed species per plate, separately. Each bacterial strain was tested in five replicates, each replicate represented by a Petri dish with 15 seeds in a Completely Randomized Design (CRD). Germination percentage and root length $(\mathrm{cm})$ were evaluated at seven days for wild poinsettia and 15 days for sourgrass and horseweed (Table 2). The data were submitted to Analysis of Variance and the means were grouped according to the Scott-Knott Test, both with significance of $p<0.05$.

Table 2 - Temperature (Temp.), photoperiod (Photop.) and incubation period (IP) in the laboratory experiment of rhizobacteria for control of wild poinsettia (Euphorbia heterophylla), sourgrass (Digitaria insularis) and horseweed (Conyza sumatrensis).

\begin{tabular}{ccccc}
\hline $\begin{array}{c}\text { Species of } \\
\text { weed }\end{array}$ & $\begin{array}{c}\text { Temp. } \\
\left({ }^{\circ} \mathrm{C}\right)\end{array}$ & $\begin{array}{c}\text { Photop. } \\
\text { (h) }\end{array}$ & $\begin{array}{c}\text { IP } \\
(\text { day })\end{array}$ & $\begin{array}{c}\text { References of } \\
\text { growth conditions }\end{array}$ \\
\hline $\begin{array}{c}E . \\
\text { heterophylla }\end{array}$ & 25 & 12 & 7 & $\begin{array}{c}\text { Suda \& Pereira, } \\
1997\end{array}$ \\
$\begin{array}{c}\text { D. insularis } \\
\begin{array}{c}\text { C. } \\
\text { sumatrensis }\end{array}\end{array}$ & 22 & 12 & 15 & Mondo et al., 2010 \\
\hline
\end{tabular}

Evaluation of the antagonistic potential of rhizobacteria against target weeds under greenhouse conditions

For the selection of bacterial strains under greenhouse conditions, the cultures of each of the isolates of Pseudomonas spp. were produced as described in the previous experiment. The production of Bacillus spp. was modified due to the problem of low final concentration of isolates $\left(10^{4}\right.$ and $\left.10^{5} \mathrm{CFU} \mathrm{mL}^{-1}\right)$ verified in the production for the in vitro experiments. In this way, we opted for the growth of isolates under agitation (120 rpm), obtaining variations in the concentrations of isolates between $10^{8}$ and $10^{9} \mathrm{CFU} \mathrm{mL}^{-1}$ (closer to the industrial reality of biological control agents). Concentrations ranged from $10^{8}$ to $10^{9} \mathrm{CFU} \mathrm{mL} \mathrm{m}^{-1}$ for Pseudomonas spp. strains.

Fifteen seeds of $E$. heterophylla, $0.01 \mathrm{~g}$ of $C$. sumatrensis seeds, and $0.03 \mathrm{~g}$ of $D$. insularis seeds were sown separately into $250 \mathrm{~mL}$ styrofoam containers $(8 \mathrm{~cm}$ diameter and $10 \mathrm{~cm}$ height) containing a sterilized soil/sand mixture (1:1) and covered with a $0.5 \mathrm{~cm}$ layer of Carolina ${ }^{\circledR} /$ coarse sand (2:1) substrate mixture. Soon after sowing, a $1.0 \times 10^{7}$ suspension of each isolate was prepared and sprayed onto the surface of the containers with an airbrush (SagymaPro, model SW-130K) with syrup volume corresponding to $200 \mathrm{~L} \mathrm{ha}^{-1}$. The containers were stored in the greenhouse and 2-mm irrigation was performed by sprinkler irrigation immediately after spraying the isolates. Containers were irrigated manually twice a day, and the temperature during the conduction of the assays varied from 14 to $29^{\circ} \mathrm{C}$ during the 14 days for $E$. heterophylla and $D$. insularis, and during the 21 days for C. sumatrensis.

The number of germinated plants was evaluated at the end of the assays. Plants were harvested and shoot and root length $(\mathrm{cm})$ were measured using a digital caliper (ABSOLUTE - Mitutoyo Sul Americana Ltda.). The roots and shoots of plants were dried at $60{ }^{\circ} \mathrm{C}$ for 24 hours in a MA035 (Marconi ${ }^{\circledR}$ ) sterilization and drying oven with forced air circulation being then weighed using a precision scale.

The following parameters were evaluated: SG (\% seed germination), RDL (radicle length), RL (root length), SL (shoot length), TL (total length), SDW (shoot dry weight), RDW (root dry weight), and TDW (total dry weight).

\section{Results and discussion}

In the 20 soil samples, a total of 41 isolates of Bacillus spp. and 33 isolates of Pseudomonas spp. was obtained. Among the isolates of Bacillus spp., 22 were discarded because they presented crystals characteristic of Bacillus thuringiensis (Berliner, 1915), which were not in the scope of the present study. Each of the samples A1, A4, A9, A10, A12, and A19 presented three isolates of the genus Bacillus without presence of crystals. For Pseudomonas isolates, the samples with the highest populations were: $\mathrm{A} 3$, col- 
lected in a bean cultivation area in Lagoa FormosaMG; A8, from a citrus orchard in Bebedouro-SP; and A14, from a maize farm in Angatuba-SP (Table 1).

In the in vitro assay, six isolates of Bacillus spp. significantly inhibited the germination of E. heterophylla seeds, namely: A1B1, A1B4, A2B1, $\mathrm{A} 2 \mathrm{~B} 2, \mathrm{~A} 11 \mathrm{~B} 2$, and $\mathrm{A} 13 \mathrm{~B} 3$ (Table 3). Of these isolates, four reduced root growth (A1B1, A2B1, A2B2, A13B3), as well as a further ten isolates of Bacillus spp. (A1B3, A2B1, A2B3, A5B3, A10B1, A10B4, A10B5, A11B1, A13B2, A13B3), as shown in Table 3.

In greenhouse assays, none of the Bacillus spp. isolates was able to reduce the germination and root and shoot growth of $E$. heterophylla plants (Table 3). On the other hand, four isolates promoted increased SDW of $E$. heterophylla (A1B3, A10B4, A11B2, and $A 13 B 2)$. These same isolates also promoted increased TDW, as observed for two other isolates (A2B1 and A10B5) (Table 3). A similar result was found by Li \& Kremer (2006), with reduction of SDW (shoot dry weight) and no reduction of RDW (root dry weight) with the application of bacteria Aeromonas hydrophila (Chester, 1901) Stainer, 1943, isolate TMR13, and Pseudomonas aureofaciens (Kluyver, 1956), isolate $\mathrm{TMH16}$, in Convolvulus arvensis L. plants. Isolate A11B2, which increased SDW under greenhouse conditions, reduced the in vitro germination percentage.
All these isolates that promoted plant growth under greenhouse conditions are among those that reduced in vitro germination or root growth. This effect is believed to be directly related to the suspension rate used in the assays, and may relate both to the concentration of bacterial cells per seed and to the concentration of regulators such as indole-3-acetic acid (IAA), since the fermentation methodology and CFU values in each assay were different. The IAA seems to play a double role according to its concentration (Chauan et al., 2009). High concentrations of IAA secreted by bacteria inhibit the germination of weed seeds (Tabatabaei et al., 2016), and are also produced by most plant growth-promoting bacteria (PGPB), being considered one of the most effective mechanisms already elucidated (Lin et al., 2012). At high concentrations, the IAA can also reduce plant root growth by its relationship with ethylene synthesis. This hormone can stimulate the transcription of 1-aminocyclopropane-1-carboxylic acid (ACC) synthase, which is the enzyme responsible for oxidizing ACC during ethylene biosynthesis (Ju \& Chang, 2015). This may be the reason why the root development of $E$. heterophylla decreased significantly after contact with some Bacillus spp. isolates in the in vitro experiment.

Table 3 - Effect of Bacillus spp. strains on wild poinsettia (Euphorbia heterophylla) control in laboratory and greenhouse conditions.

\begin{tabular}{|c|c|c|c|c|c|c|c|c|c|}
\hline \multirow[b]{2}{*}{ Strains } & \multicolumn{2}{|c|}{ Laboratory experiment } & \multicolumn{7}{|c|}{ Greenhouse experiment } \\
\hline & $\begin{array}{l}\text { SG } \\
(\%)\end{array}$ & $\begin{array}{l}\mathrm{RDL} \\
(\mathrm{cm})\end{array}$ & $\begin{array}{l}\text { SG } \\
(\%)\end{array}$ & $\begin{array}{l}\mathrm{RL} \\
(\mathrm{cm})\end{array}$ & $\begin{array}{c}\mathrm{SL} \\
(\mathrm{cm})\end{array}$ & $\begin{array}{c}\mathrm{TL} \\
(\mathrm{cm})\end{array}$ & $\begin{array}{c}\text { SDW } \\
(\mathrm{g})\end{array}$ & $\begin{array}{l}\text { RDW } \\
\text { (g) }\end{array}$ & $\begin{array}{c}\text { TDW } \\
\text { (g) }\end{array}$ \\
\hline Control & $18.6 \mathrm{a}$ & $5.2 \mathrm{a}$ & $65.3 \mathrm{a}$ & $11.1 \mathrm{a}$ & $5.0 \mathrm{a}$ & $16.2 \mathrm{a}$ & $8.7 \mathrm{c}$ & $4.7 \mathrm{a}$ & $13.4 \mathrm{~b}$ \\
\hline A1B1 & $5.3 \mathrm{~b}$ & $1.1 \mathrm{c}$ & $50.2 \mathrm{a}$ & $10.6 \mathrm{a}$ & $4.5 \mathrm{a}$ & $15.2 \mathrm{a}$ & $7.7 \mathrm{c}$ & $4.4 \mathrm{a}$ & $12.1 \mathrm{~b}$ \\
\hline A1B3 & $16.6 \mathrm{a}$ & $2.7 \mathrm{~b}$ & $58.6 \mathrm{a}$ & $11.6 \mathrm{a}$ & $4.9 \mathrm{a}$ & $16.4 \mathrm{a}$ & $12.9 \mathrm{a}$ & $4.7 \mathrm{a}$ & $18.0 \mathrm{a}$ \\
\hline A1B4 & $8.9 \mathrm{~b}$ & $3.5 \mathrm{a}$ & $64.0 \mathrm{a}$ & $11.5 \mathrm{a}$ & $4.9 \mathrm{a}$ & $16.4 \mathrm{a}$ & $8.6 \mathrm{c}$ & $4.3 \mathrm{a}$ & $13.0 \mathrm{~b}$ \\
\hline A1B5 & $14.0 \mathrm{a}$ & $3.6 \mathrm{a}$ & $85.9 \mathrm{a}$ & $9.9 \mathrm{a}$ & $4.8 \mathrm{a}$ & $14.9 \mathrm{a}$ & $8.3 \mathrm{c}$ & $4.0 \mathrm{a}$ & $12.2 \mathrm{~b}$ \\
\hline A2B1 & $6.6 \mathrm{~b}$ & $1.6 \mathrm{c}$ & $68.7 \mathrm{a}$ & $12.9 \mathrm{a}$ & $4.9 \mathrm{a}$ & $17.4 \mathrm{a}$ & $9.7 \mathrm{c}$ & $5.2 \mathrm{a}$ & $14.9 \mathrm{a}$ \\
\hline A2B2 & $6.6 \mathrm{~b}$ & $1.7 \mathrm{c}$ & $58.0 \mathrm{a}$ & $12.0 \mathrm{a}$ & $5.3 \mathrm{a}$ & $17.3 \mathrm{a}$ & $9.4 \mathrm{c}$ & $4.8 \mathrm{a}$ & $14.2 \mathrm{~b}$ \\
\hline A2B3 & $14.6 \mathrm{a}$ & $1.5 \mathrm{c}$ & $82.6 \mathrm{a}$ & $10.4 \mathrm{a}$ & $4.9 \mathrm{a}$ & $15.4 \mathrm{a}$ & $7.8 \mathrm{c}$ & $4.0 \mathrm{a}$ & $11.9 \mathrm{~b}$ \\
\hline A5B1 & $12.9 \mathrm{a}$ & $3.1 \mathrm{a}$ & $71.3 \mathrm{a}$ & $9.8 \mathrm{a}$ & $5.0 \mathrm{a}$ & $14.9 \mathrm{a}$ & $8.3 \mathrm{c}$ & $4.2 \mathrm{a}$ & $12.5 \mathrm{~b}$ \\
\hline A5B3 & $12.5 \mathrm{a}$ & $2.5 \mathrm{~b}$ & $67.8 \mathrm{a}$ & $11.9 \mathrm{a}$ & $5.0 \mathrm{a}$ & $16.9 \mathrm{a}$ & $8.6 \mathrm{c}$ & $4.5 \mathrm{a}$ & $13.2 \mathrm{~b}$ \\
\hline A5B4 & $12.1 \mathrm{a}$ & $3.8 \mathrm{a}$ & $70.1 \mathrm{a}$ & $11.7 \mathrm{a}$ & $5.0 \mathrm{a}$ & $16.7 \mathrm{a}$ & $9.0 \mathrm{c}$ & $4.1 \mathrm{a}$ & $12.9 \mathrm{~b}$ \\
\hline $\mathrm{A} 10 \mathrm{~B} 1$ & $13.4 \mathrm{a}$ & $2.4 \mathrm{~b}$ & $68.0 \mathrm{a}$ & $11.2 \mathrm{a}$ & $5.1 \mathrm{a}$ & $16.4 \mathrm{a}$ & $8.7 \mathrm{c}$ & $5.5 \mathrm{a}$ & $14.3 \mathrm{~b}$ \\
\hline A10B4 & $13.8 \mathrm{a}$ & $2.5 \mathrm{~b}$ & $65.3 \mathrm{a}$ & $10.3 a$ & $6.2 \mathrm{a}$ & $17.2 \mathrm{a}$ & $10.3 b$ & $5.3 \mathrm{a}$ & $15.6 \mathrm{a}$ \\
\hline A10B5 & $13.8 \mathrm{a}$ & $2.9 \mathrm{~b}$ & $67.8 \mathrm{a}$ & $12.7 \mathrm{a}$ & $5.2 \mathrm{a}$ & $17.9 \mathrm{a}$ & $9.5 \mathrm{c}$ & $5.2 \mathrm{a}$ & $14.8 \mathrm{a}$ \\
\hline A11B1 & $17.0 \mathrm{a}$ & $2.7 \mathrm{~b}$ & $77.8 \mathrm{a}$ & $12.1 \mathrm{a}$ & $4.9 \mathrm{a}$ & $17.0 \mathrm{a}$ & $8.2 \mathrm{c}$ & $4.5 \mathrm{a}$ & $12.7 \mathrm{~b}$ \\
\hline A11B2 & $9.7 \mathrm{~b}$ & $3.9 \mathrm{a}$ & $62.0 \mathrm{a}$ & $11.2 \mathrm{a}$ & $4.9 \mathrm{a}$ & $16.2 \mathrm{a}$ & $12.3 \mathrm{a}$ & $5.0 \mathrm{a}$ & $17.6 \mathrm{a}$ \\
\hline A11B5 & $11.6 \mathrm{a}$ & $4.2 \mathrm{a}$ & $64.2 \mathrm{a}$ & $10.3 \mathrm{a}$ & $4.9 \mathrm{a}$ & $15.4 \mathrm{a}$ & $9.2 \mathrm{c}$ & $4.3 \mathrm{a}$ & $13.6 \mathrm{~b}$ \\
\hline A13B1 & $11.3 \mathrm{a}$ & $4.1 \mathrm{a}$ & $71.3 \mathrm{a}$ & $11.9 \mathrm{a}$ & $5.1 \mathrm{a}$ & $17.0 \mathrm{a}$ & $9.0 \mathrm{c}$ & $4.2 \mathrm{a}$ & $13.0 \mathrm{~b}$ \\
\hline A13B2 & $13.4 \mathrm{a}$ & $2.5 \mathrm{~b}$ & $63.1 \mathrm{a}$ & $11.0 \mathrm{a}$ & $5.0 \mathrm{a}$ & $16.0 \mathrm{a}$ & $11.1 \mathrm{~b}$ & $4.6 \mathrm{a}$ & $16.0 \mathrm{a}$ \\
\hline A13B3 & $6.61 \mathrm{~b}$ & $1.3 \mathrm{c}$ & $77.3 \mathrm{a}$ & $10.9 \mathrm{a}$ & $4.9 \mathrm{a}$ & $15.90 \mathrm{a}$ & $8.4 \mathrm{C}$ & $4.8 \mathrm{a}$ & $13.3 \mathrm{~b}$ \\
\hline CV (\%) & 47.2 & 41.2 & 23.3 & 17.4 & 14.6 & 11.1 & 16.3 & 23.1 & 16.0 \\
\hline
\end{tabular}

Means followed by the same letter in the column do not differ statistically by the Scott-Knott Test ( $p>0.05)$. SG: seed germination, RDL: radicle length, RL: root length, SL: shoot length, TL: total length, SDW: shoot dry mass, RDW: root dry mass, TDW: total dry mass. 
Table 4 - Effect of Bacillus spp. strains on sourgrass (Digitaria insularis) control in laboratory and greenhouse conditions.

\begin{tabular}{|c|c|c|c|c|c|c|c|c|c|}
\hline \multirow[b]{2}{*}{ Strains } & \multicolumn{4}{|c|}{ Laboratory experiment } & \multicolumn{5}{|c|}{ Greenhouse experiment } \\
\hline & $\begin{array}{l}\text { SG } \\
(\%)\end{array}$ & $\begin{array}{l}\mathrm{RDL} \\
(\mathrm{cm}) \\
\end{array}$ & $\begin{array}{l}\text { SG } \\
(\%)\end{array}$ & $\begin{array}{c}\mathrm{RL} \\
(\mathrm{cm})\end{array}$ & $\begin{array}{c}\mathrm{SL} \\
(\mathrm{cm})\end{array}$ & $\begin{array}{c}\mathrm{TL} \\
(\mathrm{cm})\end{array}$ & $\begin{array}{c}\text { SDW } \\
(\mathrm{g})\end{array}$ & $\begin{array}{c}\text { RDW } \\
(\mathrm{g})\end{array}$ & $\begin{array}{c}\text { TDW } \\
(\mathrm{g}) \\
\end{array}$ \\
\hline Control & $40.0 \mathrm{a}$ & $5.2 \mathrm{a}$ & $26.6 \mathrm{a}$ & $11.1 \mathrm{a}$ & $1.2 \mathrm{a}$ & $12.3 \mathrm{a}$ & $2.0 \mathrm{a}$ & $2.5 \mathrm{a}$ & $4.5 \mathrm{a}$ \\
\hline $\mathrm{A} 1 \mathrm{~B} 1$ & $26.6 \mathrm{a}$ & $1.6 \mathrm{C}$ & $25.6 \mathrm{a}$ & $11.2 \mathrm{a}$ & $1.2 \mathrm{a}$ & $12.4 \mathrm{a}$ & $1.9 \mathrm{a}$ & $2.3 \mathrm{a}$ & $4.2 \mathrm{a}$ \\
\hline A1B3 & $22.6 \mathrm{~b}$ & $2.5 \mathrm{~b}$ & $27.1 \mathrm{a}$ & $12.2 \mathrm{a}$ & $1.3 \mathrm{a}$ & $13.6 \mathrm{a}$ & $2.3 \mathrm{a}$ & $2.0 \mathrm{a}$ & $4.2 \mathrm{a}$ \\
\hline A1B4 & $24.0 \mathrm{~b}$ & $3.1 \mathrm{a}$ & $34.5 \mathrm{a}$ & $12.4 \mathrm{a}$ & $1.2 \mathrm{a}$ & $13.6 \mathrm{a}$ & $1.8 \mathrm{a}$ & $2.1 \mathrm{a}$ & $4.0 \mathrm{a}$ \\
\hline A1B5 & $33.3 \mathrm{a}$ & $3.5 \mathrm{a}$ & $26.1 \mathrm{a}$ & $10.3 \mathrm{a}$ & $1.3 \mathrm{a}$ & $11.8 \mathrm{a}$ & $2.2 \mathrm{a}$ & $3.0 \mathrm{a}$ & $5.3 \mathrm{a}$ \\
\hline A2B1 & $26.6 \mathrm{a}$ & $1.5 \mathrm{c}$ & $31.2 \mathrm{a}$ & $9.9 \mathrm{a}$ & $1.4 \mathrm{a}$ & $11.4 \mathrm{a}$ & $2.5 \mathrm{a}$ & $2.2 \mathrm{a}$ & $4.6 \mathrm{a}$ \\
\hline A2B2 & $17.3 \mathrm{~b}$ & $3.9 \mathrm{a}$ & $27.7 \mathrm{a}$ & $11.3 \mathrm{a}$ & $1.1 \mathrm{a}$ & $12.4 \mathrm{a}$ & $1.9 \mathrm{a}$ & $2.7 \mathrm{a}$ & $4.6 \mathrm{a}$ \\
\hline A2B3 & $16.0 \mathrm{~b}$ & $4.1 \mathrm{a}$ & $31.6 \mathrm{a}$ & $10.5 \mathrm{a}$ & $1.3 \mathrm{a}$ & $11.8 \mathrm{a}$ & $2.0 \mathrm{a}$ & $2.4 \mathrm{a}$ & $4.5 \mathrm{a}$ \\
\hline A5B1 & $16.0 \mathrm{~b}$ & $2.5 \mathrm{~b}$ & $27.8 \mathrm{a}$ & $10.2 \mathrm{a}$ & $1.1 \mathrm{a}$ & $11.4 \mathrm{a}$ & $1.8 \mathrm{a}$ & $2.4 \mathrm{a}$ & $4.3 \mathrm{a}$ \\
\hline A5B3 & $21.3 b$ & $3.8 \mathrm{a}$ & $28.9 \mathrm{a}$ & $10.1 \mathrm{a}$ & $1.3 \mathrm{a}$ & $11.5 \mathrm{a}$ & $2.1 \mathrm{a}$ & $2.7 \mathrm{a}$ & $4.8 \mathrm{a}$ \\
\hline A5B4 & $20.0 \mathrm{~b}$ & $2.9 \mathrm{~b}$ & $22.8 \mathrm{a}$ & $9.9 \mathrm{a}$ & $1.2 \mathrm{a}$ & $11.2 \mathrm{a}$ & $2.1 \mathrm{a}$ & $2.6 \mathrm{a}$ & $4.7 \mathrm{a}$ \\
\hline $\mathrm{A} 10 \mathrm{~B} 1$ & $20.0 \mathrm{~b}$ & $2.7 \mathrm{~b}$ & $33.6 \mathrm{a}$ & $10.7 \mathrm{a}$ & $1.5 \mathrm{a}$ & $12.2 \mathrm{a}$ & $2.2 \mathrm{a}$ & $3.1 \mathrm{a}$ & $5.4 \mathrm{a}$ \\
\hline A10B4 & $30.6 \mathrm{a}$ & $3.6 \mathrm{a}$ & $32.8 \mathrm{a}$ & $11.1 \mathrm{a}$ & $1.6 \mathrm{a}$ & $12.7 \mathrm{a}$ & $2.8 \mathrm{a}$ & $2.5 \mathrm{a}$ & $5.3 a$ \\
\hline A10B5 & $36.0 \mathrm{a}$ & $1.1 \mathrm{c}$ & $25.4 \mathrm{a}$ & $11.6 \mathrm{a}$ & $1.3 \mathrm{a}$ & $13.0 \mathrm{a}$ & $2.1 \mathrm{a}$ & $2.5 \mathrm{a}$ & $4.6 \mathrm{a}$ \\
\hline A11B1 & $13.3 b$ & $1.3 \mathrm{c}$ & $24.0 \mathrm{a}$ & $9.3 \mathrm{a}$ & $1.2 \mathrm{a}$ & $10.5 \mathrm{a}$ & $2.1 \mathrm{a}$ & $2.6 \mathrm{a}$ & $4.8 \mathrm{a}$ \\
\hline A11B2 & $17.3 \mathrm{~b}$ & $4.2 \mathrm{a}$ & $18.6 \mathrm{a}$ & $10.8 \mathrm{a}$ & $1.3 \mathrm{a}$ & $12.2 \mathrm{a}$ & $1.5 \mathrm{a}$ & $1.9 \mathrm{a}$ & $3.4 \mathrm{a}$ \\
\hline A11B5 & $21.3 b$ & $2.5 \mathrm{~b}$ & $17.0 \mathrm{a}$ & $9.4 \mathrm{a}$ & $0.8 \mathrm{a}$ & $10.3 \mathrm{a}$ & $1.2 \mathrm{a}$ & $1.1 \mathrm{a}$ & $2.2 \mathrm{a}$ \\
\hline A13B1 & $21.3 b$ & $2.4 \mathrm{~b}$ & $19.6 \mathrm{a}$ & $10.6 \mathrm{a}$ & $1.1 \mathrm{a}$ & $11.7 \mathrm{a}$ & $2.4 \mathrm{a}$ & $3.8 \mathrm{a}$ & $6.2 \mathrm{a}$ \\
\hline A13B2 & $28.0 \mathrm{a}$ & $1.5 \mathrm{c}$ & $37.7 \mathrm{a}$ & $11.5 \mathrm{a}$ & $1.2 \mathrm{a}$ & $12.7 \mathrm{a}$ & $1.5 \mathrm{a}$ & $1.3 \mathrm{a}$ & $2.8 \mathrm{a}$ \\
\hline A13B3 & $34.6 \mathrm{a}$ & $2.6 \mathrm{~b}$ & $31.6 \mathrm{a}$ & $9.5 \mathrm{a}$ & $1.4 \mathrm{a}$ & $11.0 \mathrm{a}$ & $1.8 \mathrm{a}$ & $2.3 \mathrm{a}$ & $4.2 \mathrm{a}$ \\
\hline $\mathrm{CV}(\%)$ & 33.8 & 41.2 & 37.7 & 16.3 & 19.4 & 15.2 & 33.4 & 35.7 & 30.1 \\
\hline
\end{tabular}

Means followed by the same letter in the column do not differ statistically by the Scott-Knott Test $(p>0.05)$. SG:seed germination, RDL: radicle length, RL: root length, SL: shoot length, TL: total length, SDW: shoot dry mass, RDW: root dry mass, TDW: total dry mass

Seeds of $D$. insularis were sensitive to 12 Bacillus spp. isolates for germination and 12 Bacillus spp. isolates for in vitro root growth (Table 4). Germination decreased, on average, by $52 \%$, while radicle length had an average decrease of $59.3 \%$. Despite promising laboratory results, none of the isolates were able to cause deleterious effects on germination or seedling growth under greenhouse conditions (Table 4). This fact may be related to the different fermentation methodologies of Bacillus spp. isolates for both assays. In the laboratory, when using static fermentation, Bacillus spp. isolates reached concentrations between $10^{4}$ and $10^{5} \mathrm{CFU} \mathrm{mL}^{-1}$, values much lower than those obtained in greenhouse experiments $\left(10^{8}\right.$ and $10^{9} \mathrm{CFU} \mathrm{mL} \mathrm{m}^{-1}$ ). Considering that the rate of isolates was $1 \mathrm{~mL}$ per Petri dish (concentrations between $10^{4}$ and $10^{5} \mathrm{CFU} \mathrm{mL}^{-1}$ ) in laboratory assays and $1.0 \mathrm{x}$ $10^{7} \mathrm{CFU}$ container ${ }^{-1}$ in greenhouse assays, it is possible to infer that the concentration of bacterial cells may not be the most important factor in the inhibitory effect of these Bacillus spp. isolates on the germination or growth of $D$. insularis plants. Bioassays can evaluate the production of plant-suppressive compounds by rhizobacteria. An example of these compounds is the hydrocyanic acid, a toxic gas for plant metabolism (Kennedy et al., 2001). Thus, the different methods for obtaining isolates may have altered the production of these compounds, and the direct in vitro contact of the seed with the bacterium may have optimized the suppression effect.

The sensitivity of $C$. sumatrensis to the antagonistic action of Bacillus spp. was very high under laboratory conditions (Table 5). A total of 14 isolates reduced germination of $C$. sumatrensis seeds, with an average inhibition of $37.2 \%$. In addition, all isolates decreased root length (Table 5). Isolate A10B4 was the most effective in reducing seed germination under laboratory conditions (60.3\% inhibition), being also one of the isolates that most reduced radicle length $(73.3 \%$ inhibition). 
Table 5 - Effect of Bacillus spp. strains on horseweed (Conyza sumatrensis) control in laboratory and greenhouse conditions.

\begin{tabular}{lcc|ccccccc}
\hline & \multicolumn{1}{|c|}{ Laboratory experiment } & \multicolumn{7}{|c}{ Greenhouse experiment } \\
\cline { 2 - 10 } Strains & SG & RDL & SG & RL & SL & TL & SDW & RDW & TDW \\
& $(\%)$ & $(\mathrm{cm})$ & $(\%)$ & $(\mathrm{cm})$ & $(\mathrm{cm})$ & $(\mathrm{cm})$ & $(\mathrm{g})$ & $(\mathrm{g})$ & $(\mathrm{g})$ \\
\hline Control & $70.6 \mathrm{a}$ & $1.3 \mathrm{a}$ & $33.4 \mathrm{a}$ & $7.9 \mathrm{~b}$ & $0.8 \mathrm{a}$ & $8.8 \mathrm{~b}$ & $0.6 \mathrm{a}$ & $0.4 \mathrm{a}$ & $1.1 \mathrm{a}$ \\
A1B1 & $51.6 \mathrm{~b}$ & $0.3 \mathrm{~d}$ & $22.6 \mathrm{~b}$ & $9.3 \mathrm{a}$ & $0.8 \mathrm{a}$ & $10.1 \mathrm{a}$ & $0.6 \mathrm{a}$ & $0.4 \mathrm{a}$ & $1.1 \mathrm{a}$ \\
A1B3 & $64.0 \mathrm{a}$ & $0.5 \mathrm{c}$ & $27.6 \mathrm{~b}$ & $9.2 \mathrm{a}$ & $0.9 \mathrm{a}$ & $10.2 \mathrm{a}$ & $1.9 \mathrm{a}$ & $0.4 \mathrm{a}$ & $2.1 \mathrm{a}$ \\
A1B4 & $54.6 \mathrm{~b}$ & $0.5 \mathrm{c}$ & $18.9 \mathrm{~b}$ & $8.3 \mathrm{a}$ & $0.7 \mathrm{a}$ & $9.0 \mathrm{~b}$ & $0.8 \mathrm{a}$ & $0.4 \mathrm{a}$ & $1.2 \mathrm{a}$ \\
A1B5 & $52.0 \mathrm{~b}$ & $1.0 \mathrm{~b}$ & $40.6 \mathrm{a}$ & $7.9 \mathrm{~b}$ & $0.6 \mathrm{a}$ & $8.6 \mathrm{~b}$ & $0.6 \mathrm{a}$ & $0.7 \mathrm{a}$ & $1.3 \mathrm{a}$ \\
A2B1 & $65.3 \mathrm{a}$ & $0.6 \mathrm{c}$ & $43.1 \mathrm{a}$ & $7.5 \mathrm{~b}$ & $0.8 \mathrm{a}$ & $8.4 \mathrm{~b}$ & $0.5 \mathrm{a}$ & $0.4 \mathrm{a}$ & $0.9 \mathrm{a}$ \\
A2B2 & $46.6 \mathrm{~b}$ & $0.4 \mathrm{~d}$ & $15.4 \mathrm{~b}$ & $6.4 \mathrm{~b}$ & $0.9 \mathrm{a}$ & $7.3 \mathrm{~b}$ & $0.8 \mathrm{a}$ & $0.4 \mathrm{a}$ & $1.3 \mathrm{a}$ \\
A2B3 & $53.3 \mathrm{~b}$ & $0.2 \mathrm{~d}$ & $20.2 \mathrm{~b}$ & $7.4 \mathrm{~b}$ & $0.7 \mathrm{a}$ & $8.2 \mathrm{~b}$ & $0.8 \mathrm{a}$ & $0.4 \mathrm{a}$ & $1.2 \mathrm{a}$ \\
A5B1 & $53.3 \mathrm{~b}$ & $0.5 \mathrm{c}$ & $33.8 \mathrm{a}$ & $7.7 \mathrm{~b}$ & $0.7 \mathrm{a}$ & $8.5 \mathrm{~b}$ & $0.7 \mathrm{a}$ & $0.5 \mathrm{a}$ & $1.2 \mathrm{a}$ \\
A5B3 & $54.6 \mathrm{~b}$ & $0.5 \mathrm{c}$ & $29.9 \mathrm{a}$ & $9.2 \mathrm{a}$ & $0.7 \mathrm{a}$ & $10.0 \mathrm{a}$ & $0.7 \mathrm{a}$ & $0.5 \mathrm{a}$ & $1.3 \mathrm{a}$ \\
A5B4 & $50.6 \mathrm{~b}$ & $0.3 \mathrm{~d}$ & $33.1 \mathrm{a}$ & $7.2 \mathrm{~b}$ & $0.8 \mathrm{a}$ & $8.0 \mathrm{~b}$ & $0.5 \mathrm{a}$ & $0.5 \mathrm{a}$ & $1.0 \mathrm{a}$ \\
A10B1 & $50.6 \mathrm{~b}$ & $0.5 \mathrm{c}$ & $19.8 \mathrm{~b}$ & $7.2 \mathrm{~b}$ & $0.7 \mathrm{a}$ & $8.0 \mathrm{~b}$ & $0.7 \mathrm{a}$ & $0.4 \mathrm{a}$ & $1.1 \mathrm{a}$ \\
A10B4 & $28.0 \mathrm{c}$ & $0.3 \mathrm{~d}$ & $39.6 \mathrm{a}$ & $8.0 \mathrm{~b}$ & $0.9 \mathrm{a}$ & $9.0 \mathrm{~b}$ & $0.7 \mathrm{a}$ & $0.5 \mathrm{a}$ & $1.3 \mathrm{a}$ \\
A10B5 & $69.3 \mathrm{a}$ & $0.4 \mathrm{c}$ & $16.1 \mathrm{~b}$ & $8.9 \mathrm{a}$ & $0.7 \mathrm{a}$ & $9.7 \mathrm{a}$ & $0.7 \mathrm{a}$ & $0.4 \mathrm{a}$ & $1.1 \mathrm{a}$ \\
A11B1 & $62.6 \mathrm{a}$ & $0.4 \mathrm{c}$ & $25.3 \mathrm{~b}$ & $9.3 \mathrm{a}$ & $0.8 \mathrm{a}$ & $10.1 \mathrm{a}$ & $0.7 \mathrm{a}$ & $0.5 \mathrm{a}$ & $1.3 \mathrm{a}$ \\
A11B2 & $64.0 \mathrm{a}$ & $0.4 \mathrm{c}$ & $56.5 \mathrm{a}$ & $8.0 \mathrm{~b}$ & $0.8 \mathrm{a}$ & $8.9 \mathrm{~b}$ & $0.6 \mathrm{a}$ & $0.4 \mathrm{a}$ & $1.1 \mathrm{a}$ \\
A11B5 & $50.6 \mathrm{~b}$ & $0.3 \mathrm{~d}$ & $51.4 \mathrm{a}$ & $8.7 \mathrm{a}$ & $0.8 \mathrm{a}$ & $9.5 \mathrm{a}$ & $0.5 \mathrm{a}$ & $0.3 \mathrm{a}$ & $0.9 \mathrm{a}$ \\
A13B1 & $37.3 \mathrm{c}$ & $0.3 \mathrm{~d}$ & $33.1 \mathrm{a}$ & $8.3 \mathrm{a}$ & $0.9 \mathrm{a}$ & $9.2 \mathrm{a}$ & $0.7 \mathrm{a}$ & $0.7 \mathrm{a}$ & $1.4 \mathrm{a}$ \\
A13B2 & $44.0 \mathrm{~b}$ & $0.4 \mathrm{c}$ & $38.3 \mathrm{a}$ & $8.9 \mathrm{a}$ & $0.9 \mathrm{a}$ & $9.8 \mathrm{a}$ & $0.7 \mathrm{a}$ & $0.4 \mathrm{a}$ & $1.2 \mathrm{a}$ \\
A13B3 & $46.6 \mathrm{~b}$ & $0.4 \mathrm{c}$ & $21.4 \mathrm{~b}$ & $7.5 \mathrm{~b}$ & $0.9 \mathrm{a}$ & $8.4 \mathrm{~b}$ & $2.4 \mathrm{a}$ & $0.4 \mathrm{a}$ & $2.9 \mathrm{a}$ \\
\hline CV (\%) & 24.1 & 30.9 & 44.1 & 14.6 & 20.7 & 13.3 & 128.1 & 51.9 & 78.6 \\
\hline
\end{tabular}

Means followed by the same letter in the column do not differ statistically by the Scott-Knott Test $(p>0.05)$. SG:seed germination, RDL: radicle length, RL: root length, SL: shoot length, TL: total length, SDW: shoot dry mass, RDW: root dry mass, TDW: total dry mass

In the greenhouse experiment, nine Bacillus spp. isolates decreased seed germination, with an average inhibition of $37.7 \%$, but none was able to reduce root growth (Table 5). On the other hand, isolates A1B1, A1B3, A1B4, A10B5, and A11B1 promoted root growth, showing that the mechanism of action in inhibiting germination for these isolates may not be related to bacterial IAA secretion, since the concentration that reduces germination is also detrimental to root growth (Chauhan et al., 2009). A similar result was found by Carvalho et al. (2011) with isolate 80-20 from Bacillus pumilus Meyer and Gottheil, 1901. This isolate was one of the most efficient in inhibiting lettuce seed germination; however, it was the only one among 25 isolates that did not reduce the growth of wheat coleoptiles.

Isolates A1B3, A10B5, and A11B1 from Bacillus spp. did not present an in vitro inhibitory effect on the germination of $C$. sumatrensis seeds, but reduced seed germination under greenhouse conditions. Three factors can be considered as the possible causes of this effect. The first is the temperature difference between the two experimental conditions; the second is the different methods of producing bacterial isolates in the respective experiments; and the third is the rate applied per experimental unit (Petri dish or container). The temperature conditions in the greenhouse may have benefited the development of bacterial strains, since it varied between 18 and $29^{\circ} \mathrm{C}$, reaching values close to the fermentation temperature $\left(29^{\circ} \mathrm{C}\right)$. Laboratory conditions, in turn, included the constant temperature of $22^{\circ} \mathrm{C}$, considered favorable to the germination of horseweed seeds (Nandula et al., 2006). Regarding the production of strains, the different methodologies may have altered the secretion of metabolites such as hydrocyanic acid by bacteria, as previously mentioned. Furthermore, the rate of isolates was different for both assays. In the laboratory assay, the rate was $10^{4}-10^{5} \mathrm{CFU}$ Petri plate ${ }^{-1}$; for greenhouse assays, the rate was $1.0 \times 10^{7}$ CFU container $^{-1}$. According to Begonia et al. (1998), bacterial cell concentration plays a key role in the deleterious effect on 
weeds, as it can directly influence root colonization by bacteria. These authors verified germination inhibition and gradual reduction in seedling growth with the application of supernatant-free fluorescent bacteria isolates at rates of $10^{7}, 10^{8}$, and $10^{9} \mathrm{CFU} \mathrm{g} \mathrm{soil}{ }^{-1}$. Isolate VLBR-01 reduced seed germination and root growth in the three rates tested, while isolate V239 reduced germination only at the rate of $10^{9} \mathrm{CFU} \mathrm{g} \mathrm{soil-1}$. In this same study, bacterial concentrations in the root, rhizosphere, and soil followed the same trend of the applied rates.

The main difference in cultivation between the fermentation methods of the bacterial isolates is the oxygenation of the culture medium, provided by the shaking process in the method defined for greenhouse experiments. Oxygen is the essential element in most metabolic processes of aerobic organisms because it is an electron acceptor. Its deficiency can lead to re- duced efficiency of NADH and NADPH oxidation, essential reactions for ATP production, and low flow through the tricarboxylic acid (TCA) cycle (Zhang \& Xiu, 2009). Katzer et al. (2001) found that the production of secondary metabolites such as hydrocyanic acid by bacteria is not only influenced by factors such as restriction of nitrogen or phosphate, but also may depend on oxygen limitation during the fermentation process.

Six isolates of Pseudomonas spp. significantly reduced the in vitro germination of $E$. heterophylla seeds, with an average inhibition of $80.3 \%$. These isolates were: A1P6, A4XP4, A8P2, A8P8, A8XP10, and A9P2 (Table 6). With the exception of isolate A9P2, these isolates also reduced seedling root length, as observed for these isolates (A1XP10, A3XP14, A8P4, A10P5, A18XP4, A14P4, A14P2, A13XP8, A11P12, A11P11) (Table 6).

Table 6 - Effect of Pseudomonas spp. strains on wild poinsettia (Euphorbia heterophylla) control in laboratory and greenhouse conditions.

\begin{tabular}{|c|c|c|c|c|c|c|c|c|c|}
\hline \multirow[b]{2}{*}{ Strains } & \multicolumn{2}{|c|}{ Laboratory. experiment } & \multicolumn{7}{|c|}{ Greenhouse experiment } \\
\hline & $\begin{array}{l}\text { SG } \\
(\%)\end{array}$ & $\begin{array}{l}\mathrm{RDL} \\
(\mathrm{cm})\end{array}$ & $\begin{array}{l}\text { SG } \\
(\%)\end{array}$ & $\begin{array}{c}\mathrm{RL} \\
(\mathrm{cm})\end{array}$ & $\begin{array}{c}\mathrm{SL} \\
(\mathrm{cm})\end{array}$ & $\begin{array}{c}\mathrm{TL} \\
(\mathrm{cm})\end{array}$ & $\begin{array}{c}\text { SDW } \\
(\mathrm{g})\end{array}$ & $\begin{array}{c}\text { RDW } \\
(\mathrm{g})\end{array}$ & $\begin{array}{c}\text { TDW } \\
\text { (g) }\end{array}$ \\
\hline Control & $56.0 \mathrm{a}$ & $7.5 \mathrm{a}$ & $52.0 \mathrm{a}$ & $14.8 \mathrm{a}$ & $3.5 \mathrm{a}$ & $18.3 \mathrm{a}$ & $18.5 \mathrm{a}$ & $8.9 \mathrm{~b}$ & $27.4 \mathrm{a}$ \\
\hline A1P6 & $12.2 \mathrm{~b}$ & $2.1 \mathrm{~b}$ & $45.5 \mathrm{a}$ & $16.2 \mathrm{a}$ & $3.5 \mathrm{a}$ & $19.6 \mathrm{a}$ & $19.9 \mathrm{a}$ & $8.6 \mathrm{~b}$ & $28.4 \mathrm{a}$ \\
\hline $\mathrm{A} 1 \mathrm{XP} 10$ & $52.0 \mathrm{a}$ & $2.2 \mathrm{~b}$ & $45.3 \mathrm{a}$ & $15.4 \mathrm{a}$ & $3.5 \mathrm{a}$ & $18.9 \mathrm{a}$ & $14.1 \mathrm{~b}$ & $8.6 \mathrm{~b}$ & $22.8 \mathrm{a}$ \\
\hline A2P6 & $38.8 \mathrm{a}$ & $4.6 \mathrm{a}$ & $57.0 \mathrm{a}$ & $14.0 \mathrm{a}$ & $3.4 \mathrm{a}$ & $17.4 \mathrm{a}$ & $18.2 \mathrm{a}$ & $8.6 \mathrm{~b}$ & $26.7 \mathrm{a}$ \\
\hline A2XP3 & $49.3 \mathrm{a}$ & $4.1 \mathrm{a}$ & $52.0 \mathrm{a}$ & $15.1 \mathrm{a}$ & $3.4 \mathrm{a}$ & $18.5 \mathrm{a}$ & $17.8 \mathrm{a}$ & $8.7 \mathrm{~b}$ & $26.6 \mathrm{a}$ \\
\hline A3P2 & $52.5 \mathrm{a}$ & $5.5 \mathrm{a}$ & $58.0 \mathrm{a}$ & $15.8 \mathrm{a}$ & $3.6 \mathrm{a}$ & $19.3 \mathrm{a}$ & $18.1 \mathrm{a}$ & $7.6 \mathrm{~b}$ & $25.4 \mathrm{a}$ \\
\hline A3P6 & $52.5 \mathrm{a}$ & $4.9 \mathrm{a}$ & $51.0 \mathrm{a}$ & $15.6 \mathrm{a}$ & $3.3 \mathrm{a}$ & $18.9 \mathrm{a}$ & $17.8 \mathrm{a}$ & $7.9 \mathrm{~b}$ & $25.5 \mathrm{a}$ \\
\hline A3XP10 & $45.7 \mathrm{a}$ & $6.1 \mathrm{a}$ & $52.5 \mathrm{a}$ & $13.4 \mathrm{a}$ & $3.4 \mathrm{a}$ & $16.9 \mathrm{a}$ & $16.6 \mathrm{~b}$ & $6.3 \mathrm{~b}$ & $22.3 \mathrm{a}$ \\
\hline A3XP11 & $44.5 \mathrm{a}$ & $7.1 \mathrm{a}$ & $53.0 \mathrm{a}$ & $14.2 \mathrm{a}$ & $3.3 \mathrm{a}$ & $17.4 \mathrm{a}$ & $15.3 b$ & $7.8 \mathrm{~b}$ & $23.2 \mathrm{a}$ \\
\hline A3XP12 & $45.7 \mathrm{a}$ & $5.6 \mathrm{a}$ & $39.0 \mathrm{a}$ & $11.5 \mathrm{a}$ & $3.6 \mathrm{a}$ & $15.4 \mathrm{a}$ & $17.0 \mathrm{~b}$ & $7.8 \mathrm{~b}$ & $24.7 \mathrm{a}$ \\
\hline А3ХP14 & $40.0 \mathrm{a}$ & $1.3 \mathrm{~b}$ & $50.7 \mathrm{a}$ & $15.9 \mathrm{a}$ & $3.7 \mathrm{a}$ & $19.7 \mathrm{a}$ & $13.7 \mathrm{~b}$ & $8.3 \mathrm{~b}$ & $22.0 \mathrm{a}$ \\
\hline A3XP15 & $40.0 \mathrm{a}$ & $5.1 \mathrm{a}$ & $47.0 \mathrm{a}$ & $14.3 \mathrm{a}$ & $3.5 \mathrm{a}$ & $17.8 \mathrm{a}$ & $18.2 \mathrm{a}$ & $10.3 \mathrm{a}$ & $29.1 \mathrm{a}$ \\
\hline A4XP4 & $18.6 \mathrm{~b}$ & $1.1 \mathrm{~b}$ & $49.3 \mathrm{a}$ & $14.9 \mathrm{a}$ & $3.5 \mathrm{a}$ & $18.4 \mathrm{a}$ & $18.3 \mathrm{a}$ & $8.6 \mathrm{~b}$ & $26.8 \mathrm{a}$ \\
\hline A7P1 & $42.2 \mathrm{a}$ & $4.6 \mathrm{a}$ & $55.5 \mathrm{a}$ & $16.7 \mathrm{a}$ & $3.6 \mathrm{a}$ & $20.2 \mathrm{a}$ & $16.5 \mathrm{~b}$ & $10.8 \mathrm{a}$ & $28.5 \mathrm{a}$ \\
\hline A8P2 & $3.5 \mathrm{~b}$ & $1.9 \mathrm{~b}$ & $48.4 \mathrm{a}$ & $12.9 \mathrm{a}$ & $3.7 \mathrm{a}$ & $16.8 \mathrm{a}$ & $19.6 \mathrm{a}$ & $7.1 \mathrm{~b}$ & $26.5 \mathrm{a}$ \\
\hline A8P4 & $46.6 \mathrm{a}$ & $1.7 \mathrm{~b}$ & $40.0 \mathrm{a}$ & $11.3 \mathrm{a}$ & $2.9 \mathrm{a}$ & $14.1 \mathrm{a}$ & $15.5 b$ & $6.5 \mathrm{~b}$ & $21.5 \mathrm{a}$ \\
\hline A8P8 & $15.7 \mathrm{~b}$ & $1.2 b$ & $49.8 \mathrm{a}$ & $14.0 \mathrm{a}$ & $3.2 \mathrm{a}$ & $17.1 \mathrm{a}$ & $19.9 \mathrm{a}$ & $7.1 \mathrm{~b}$ & $26.9 \mathrm{a}$ \\
\hline A8XP10 & $5.3 b$ & $0.5 \mathrm{~b}$ & $50.7 \mathrm{a}$ & $14.5 \mathrm{a}$ & $3.5 \mathrm{a}$ & $18.0 \mathrm{a}$ & $14.9 \mathrm{~b}$ & $8.9 \mathrm{~b}$ & $23.9 \mathrm{a}$ \\
\hline A8XP9 & $35.4 \mathrm{a}$ & $6.8 \mathrm{a}$ & $54.3 \mathrm{a}$ & $17.3 \mathrm{a}$ & $3.6 \mathrm{a}$ & $20.7 \mathrm{a}$ & $16.8 \mathrm{~b}$ & $9.4 \mathrm{~b}$ & $26.7 \mathrm{a}$ \\
\hline A9P1 & $36.5 \mathrm{a}$ & $4.4 \mathrm{a}$ & $63.6 \mathrm{a}$ & $14.3 \mathrm{a}$ & $3.5 \mathrm{a}$ & $17.9 \mathrm{a}$ & $17.9 \mathrm{a}$ & $7.6 \mathrm{~b}$ & $25.1 \mathrm{a}$ \\
\hline A9P2 & $10.5 b$ & $4.2 \mathrm{a}$ & $42.6 \mathrm{a}$ & $15.0 \mathrm{a}$ & $4.0 \mathrm{a}$ & $19.1 \mathrm{a}$ & $20.6 \mathrm{a}$ & $8.9 \mathrm{~b}$ & $29.4 \mathrm{a}$ \\
\hline A9XP2 & $44.5 \mathrm{a}$ & $4.9 \mathrm{a}$ & $47.4 \mathrm{a}$ & $15.6 \mathrm{a}$ & $3.5 \mathrm{a}$ & $19.0 \mathrm{a}$ & $18.5 \mathrm{a}$ & $11.5 \mathrm{a}$ & $31.0 \mathrm{a}$ \\
\hline A10P5 & $30.6 \mathrm{a}$ & $3.7 \mathrm{~b}$ & $42.7 \mathrm{a}$ & $13.6 \mathrm{a}$ & $3.7 \mathrm{a}$ & $17.2 \mathrm{a}$ & $19.6 \mathrm{a}$ & $7.9 \mathrm{~b}$ & $26.6 \mathrm{a}$ \\
\hline A10XP5 & $44.5 \mathrm{a}$ & $5.5 \mathrm{a}$ & $62.4 \mathrm{a}$ & $15.5 \mathrm{a}$ & $3.6 \mathrm{a}$ & $19.1 \mathrm{a}$ & $15.7 \mathrm{~b}$ & $7.4 \mathrm{~b}$ & $23.1 \mathrm{a}$ \\
\hline $\mathrm{A} 11 \mathrm{P} 11$ & $42.6 \mathrm{a}$ & $2.8 \mathrm{~b}$ & $46.7 \mathrm{a}$ & $15.0 \mathrm{a}$ & $3.5 a$ & $18.5 \mathrm{a}$ & $18.4 \mathrm{a}$ & $8.6 \mathrm{~b}$ & $26.9 \mathrm{a}$ \\
\hline A11P12 & $53.3 \mathrm{a}$ & $2.4 \mathrm{~b}$ & $40.0 \mathrm{a}$ & $13.4 \mathrm{a}$ & $3.6 \mathrm{a}$ & $16.9 \mathrm{a}$ & $19.2 \mathrm{a}$ & $7.7 \mathrm{~b}$ & $26.1 \mathrm{a}$ \\
\hline
\end{tabular}


Cont. Table 6

\begin{tabular}{|c|c|c|c|c|c|c|c|c|c|c|}
\hline \multirow[b]{2}{*}{ Strains } & \multicolumn{2}{|c|}{ Laboratory. experiment } & \multicolumn{8}{|c|}{ Greenhouse experiment } \\
\hline & $\begin{array}{l}\text { SG } \\
(\%)\end{array}$ & $\begin{array}{l}\mathrm{RDL} \\
(\mathrm{cm})\end{array}$ & $\begin{array}{l}S G \\
\%)\end{array}$ & $\begin{array}{c}\mathrm{RL} \\
(\mathrm{cm})\end{array}$ & $\begin{array}{c}\mathrm{SL} \\
(\mathrm{cm})\end{array}$ & $\begin{array}{c}\mathrm{TL} \\
(\mathrm{cm})\end{array}$ & $\begin{array}{c}\text { SDW } \\
\text { (g) }\end{array}$ & $\begin{array}{c}\text { RDW } \\
(\mathrm{g})\end{array}$ & & g) \\
\hline $\mathrm{A} 11 \mathrm{XP1}$ & $44.0 \mathrm{a}$ & $4.6 \mathrm{a}$ & $36.0 \mathrm{a}$ & $13.1 \mathrm{a}$ & & $3.6 \mathrm{a}$ & $16.6 \mathrm{a}$ & $19.1 \mathrm{a}$ & $7.6 \mathrm{~b}$ & $25.8 \mathrm{a}$ \\
\hline A11XP13 & $28.5 \mathrm{a}$ & $5.5 \mathrm{a}$ & $52.0 \mathrm{a}$ & $15.9 \mathrm{a}$ & & $3.8 \mathrm{a}$ & $19.7 \mathrm{a}$ & $22.1 \mathrm{a}$ & $12.2 \mathrm{a}$ & $35.0 \mathrm{a}$ \\
\hline A13XP8 & $32.0 \mathrm{a}$ & $0.8 \mathrm{~b}$ & $57.3 \mathrm{a}$ & $15.7 \mathrm{a}$ & & $3.9 \mathrm{a}$ & $19.6 \mathrm{a}$ & $17.8 \mathrm{a}$ & $9.6 \mathrm{~b}$ & $26.6 \mathrm{a}$ \\
\hline A14P2 & $34.6 \mathrm{a}$ & $1.1 \mathrm{~b}$ & $54.7 \mathrm{a}$ & $15.4 \mathrm{a}$ & & $3.9 \mathrm{a}$ & $19.3 \mathrm{a}$ & $15.8 b$ & $8.4 \mathrm{~b}$ & $24.3 \mathrm{a}$ \\
\hline A14P4 & $46.6 \mathrm{a}$ & $1.6 \mathrm{~b}$ & $61.3 \mathrm{a}$ & $14.3 \mathrm{a}$ & & $3.8 \mathrm{a}$ & $18.2 \mathrm{a}$ & $14.5 b$ & $8.3 \mathrm{~b}$ & $22.9 \mathrm{a}$ \\
\hline A16P4 & $33.2 \mathrm{a}$ & $5.0 \mathrm{a}$ & $39.0 \mathrm{a}$ & $14.8 \mathrm{a}$ & & $3.8 \mathrm{a}$ & $18.7 \mathrm{a}$ & $20.3 \mathrm{a}$ & $8.6 \mathrm{~b}$ & $28.8 \mathrm{a}$ \\
\hline A18XP4 & $42.6 \mathrm{a}$ & $1.8 \mathrm{~b}$ & $56.7 \mathrm{a}$ & $16.3 \mathrm{a}$ & & $3.8 \mathrm{a}$ & $20.1 \mathrm{a}$ & $15.0 \mathrm{~b}$ & $9.1 \mathrm{~b}$ & $24.0 \mathrm{a}$ \\
\hline A19XP2 & $45.6 \mathrm{a}$ & $4.6 \mathrm{a}$ & $52.0 \mathrm{a}$ & $18.2 \mathrm{a}$ & & $3.6 \mathrm{a}$ & $21.6 \mathrm{a}$ & $18.5 \mathrm{a}$ & $14.4 \mathrm{a}$ & $35.3 \mathrm{a}$ \\
\hline CV (\%) & 49.1 & 49.3 & 25.6 & 19.3 & & 15.8 & 16.6 & 19.2 & 30.1 & 21.8 \\
\hline
\end{tabular}

Means followed by the same letter in the column do not differ statistically by the Scott-Knott Test $(p>0.05)$. SG: seed germination, RDL: radicle length, RL: root length, SL: shoot length, TL: total length, SDW: shoot dry mass, RDW: root dry mass, TDW: total dry mass

Under greenhouse conditions, isolates reduced neither seed germination nor root and shoot length of E. heterophylla plants (Table 6). However, 13 isolates reduced SDW, which showed an average inhibition of $16.2 \%$. Five isolates promoted increased RDW (A3XP15, A7P1, A9XP2, A11XP13, and A19XP2). Some Bacillus spp. showed similar behavior, except that none of these reduced germination or growth. Despite having a growth promoting effect on $E$. heterophylla, these isolates inhibited the germination of
C. sumatrensis (Table 8), and some of them inhibited germination in $D$. insularis (Table 7). Different types of plants may influence the behavior of DRB, either directly with colonization, growth, and physiology, or indirectly by affecting native microflora (Åström \& Gerhardson, 1988). Isolate D7 from Pseudomonas fluorescens (Migula, 1895), for example, was shown to inhibit the germination of several weed species; notwithstanding, it promoted growth of the weed species Brassica napus L. (Kennedy et al., 2001).

Table 7 - Effect of Pseudomonas spp. strains on sourgrass (Digitaria insularis) control in laboratory and greenhouse conditions.

\begin{tabular}{lcc|ccccccc}
\hline & \multicolumn{7}{|c|}{ Laboratory experiment } & \multicolumn{7}{|c}{ Greenhouse experiment } \\
\cline { 2 - 9 } Strains & SG & RDL & SG & RL & SL & TL & SDW & RDW & TDW \\
& $\%$ & $(\mathrm{~cm})$ & $\%$ & $(\mathrm{~cm})$ & $(\mathrm{cm})$ & $(\mathrm{cm})$ & $(\mathrm{g})$ & $(\mathrm{g})$ & $(\mathrm{g})$ \\
\hline Control & $42.6 \mathrm{a}$ & $0.9 \mathrm{a}$ & $42.5 \mathrm{a}$ & $9.8 \mathrm{a}$ & $0.8 \mathrm{a}$ & $10.6 \mathrm{a}$ & $0.98 \mathrm{~b}$ & $1.3 \mathrm{~b}$ & $2.3 \mathrm{~b}$ \\
A1P6 & $38.7 \mathrm{a}$ & $0.7 \mathrm{a}$ & $34.5 \mathrm{a}$ & $10.3 \mathrm{a}$ & $0.7 \mathrm{a}$ & $11.0 \mathrm{a}$ & $1.39 \mathrm{a}$ & $1.5 \mathrm{a}$ & $2.9 \mathrm{a}$ \\
A1XP10 & $24.0 \mathrm{~b}$ & $0.3 \mathrm{~b}$ & $53.9 \mathrm{a}$ & $9.3 \mathrm{~b}$ & $0.8 \mathrm{a}$ & $10.2 \mathrm{~b}$ & $0.96 \mathrm{~b}$ & $1.2 \mathrm{~b}$ & $2.1 \mathrm{~b}$ \\
A2P6 & $29.2 \mathrm{~b}$ & $0.9 \mathrm{a}$ & $44.6 \mathrm{a}$ & $9.1 \mathrm{~b}$ & $0.8 \mathrm{a}$ & $10.0 \mathrm{~b}$ & $0.94 \mathrm{~b}$ & $0.9 \mathrm{~b}$ & $1.8 \mathrm{~b}$ \\
A2XP3 & $57.3 \mathrm{a}$ & $1.0 \mathrm{a}$ & $41.0 \mathrm{a}$ & $8.6 \mathrm{~b}$ & $0.7 \mathrm{a}$ & $9.4 \mathrm{~b}$ & $1.01 \mathrm{~b}$ & $1.0 \mathrm{~b}$ & $2.0 \mathrm{~b}$ \\
A3P2 & $19.3 \mathrm{~b}$ & $0.7 \mathrm{a}$ & $45.4 \mathrm{a}$ & $8.7 \mathrm{~b}$ & $0.6 \mathrm{a}$ & $9.4 \mathrm{~b}$ & $0.90 \mathrm{~b}$ & $0.9 \mathrm{~b}$ & $1.7 \mathrm{~b}$ \\
A3P6 & $35.3 \mathrm{a}$ & $0.9 \mathrm{a}$ & $38.4 \mathrm{a}$ & $8.5 \mathrm{~b}$ & $0.6 \mathrm{a}$ & $9.2 \mathrm{~b}$ & $0.80 \mathrm{~b}$ & $0.9 \mathrm{~b}$ & $1.7 \mathrm{~b}$ \\
A3XP10 & $41.4 \mathrm{a}$ & $0.8 \mathrm{a}$ & $37.1 \mathrm{a}$ & $9.2 \mathrm{~b}$ & $0.6 \mathrm{a}$ & $9.8 \mathrm{~b}$ & $0.78 \mathrm{~b}$ & $0.9 \mathrm{~b}$ & $1.6 \mathrm{~b}$ \\
A3XP11 & $31.7 \mathrm{~b}$ & $0.5 \mathrm{~b}$ & $48.5 \mathrm{a}$ & $8.9 \mathrm{~b}$ & $0.9 \mathrm{a}$ & $9.9 \mathrm{~b}$ & $0.98 \mathrm{~b}$ & $0.9 \mathrm{~b}$ & $1.8 \mathrm{~b}$ \\
A3XP12 & $4.8 \mathrm{~b}$ & $0.2 \mathrm{~b}$ & $39.7 \mathrm{a}$ & $10.1 \mathrm{a}$ & $0.8 \mathrm{a}$ & $11.0 \mathrm{a}$ & $0.90 \mathrm{~b}$ & $0.9 \mathrm{~b}$ & $1.8 \mathrm{~b}$ \\
A3XP14 & $4.8 \mathrm{~b}$ & $0.2 \mathrm{~b}$ & $34.9 \mathrm{a}$ & $8.6 \mathrm{~b}$ & $0.7 \mathrm{a}$ & $9.3 \mathrm{~b}$ & $0.89 \mathrm{~b}$ & $0.8 \mathrm{~b}$ & $1.7 \mathrm{~b}$ \\
A3XP15 & $42.6 \mathrm{a}$ & $0.8 \mathrm{a}$ & $35.0 \mathrm{a}$ & $8.6 \mathrm{~b}$ & $0.8 \mathrm{a}$ & $9.5 \mathrm{~b}$ & $1.00 \mathrm{~b}$ & $1.1 \mathrm{~b}$ & $2.0 \mathrm{~b}$ \\
A4XP4 & $41.3 \mathrm{a}$ & $0.9 \mathrm{a}$ & $49.1 \mathrm{a}$ & $8.4 \mathrm{~b}$ & $0.7 \mathrm{a}$ & $9.2 \mathrm{~b}$ & $1.00 \mathrm{~b}$ & $1.0 \mathrm{~b}$ & $2.0 \mathrm{~b}$ \\
A7P1 & $21.9 \mathrm{~b}$ & $0.5 \mathrm{~b}$ & $42.9 \mathrm{a}$ & $9.3 \mathrm{~b}$ & $0.8 \mathrm{a}$ & $10.2 \mathrm{~b}$ & $1.08 \mathrm{~b}$ & $1.2 \mathrm{~b}$ & $2.3 \mathrm{~b}$ \\
A8P2 & $27.1 \mathrm{~b}$ & $0.3 \mathrm{~b}$ & $35.5 \mathrm{a}$ & $10.3 \mathrm{a}$ & $0.7 \mathrm{a}$ & $11.0 \mathrm{a}$ & $1.31 \mathrm{a}$ & $1.6 \mathrm{a}$ & $2.9 \mathrm{a}$ \\
A8P4 & $21.3 \mathrm{~b}$ & $0.6 \mathrm{~b}$ & $39.7 \mathrm{a}$ & $8.9 \mathrm{~b}$ & $0.8 \mathrm{a}$ & $9.7 \mathrm{~b}$ & $0.91 \mathrm{~b}$ & $0.9 \mathrm{~b}$ & $1.8 \mathrm{~b}$ \\
A8P8 & $50.6 \mathrm{a}$ & $0.5 \mathrm{~b}$ & $41.3 \mathrm{a}$ & $11.7 \mathrm{a}$ & $0.7 \mathrm{a}$ & $12.4 \mathrm{a}$ & $1.25 \mathrm{a}$ & $1.5 \mathrm{a}$ & $2.8 \mathrm{a}$ \\
\hline
\end{tabular}


Cont. Table 7

\begin{tabular}{|c|c|c|c|c|c|c|c|c|c|}
\hline \multirow[b]{2}{*}{ Strains } & \multicolumn{2}{|c|}{ Laboratory experiment } & \multicolumn{7}{|c|}{ Greenhouse experiment } \\
\hline & $\begin{array}{c}S G \\
\%\end{array}$ & $\begin{array}{l}\mathrm{RDL} \\
(\mathrm{cm})\end{array}$ & $\begin{array}{c}S G \\
\%\end{array}$ & $\begin{array}{l}\mathrm{RL} \\
(\mathrm{cm})\end{array}$ & $\begin{array}{c}\mathrm{SL} \\
(\mathrm{cm})\end{array}$ & $\begin{array}{c}\mathrm{TL} \\
(\mathrm{cm})\end{array}$ & $\begin{array}{c}\text { SDW } \\
(\mathrm{g})\end{array}$ & $\begin{array}{c}\text { RDW } \\
\text { (g) }\end{array}$ & $\begin{array}{c}\text { TDW } \\
(\mathrm{g})\end{array}$ \\
\hline A8XP10 & $29.1 \mathrm{~b}$ & $0.4 \mathrm{~b}$ & $49.6 \mathrm{a}$ & $7.8 \mathrm{~b}$ & $0.7 \mathrm{a}$ & $8.6 \mathrm{~b}$ & $1.02 \mathrm{~b}$ & $1.0 \mathrm{~b}$ & $2.0 \mathrm{~b}$ \\
\hline A8XP9 & $43.8 \mathrm{a}$ & $0.9 \mathrm{a}$ & $33.6 \mathrm{a}$ & $9.6 \mathrm{a}$ & $1.0 \mathrm{a}$ & $10.8 \mathrm{a}$ & $1.24 \mathrm{a}$ & $1.6 \mathrm{a}$ & $2.9 \mathrm{a}$ \\
\hline A9P1 & $40.2 \mathrm{a}$ & $0.9 \mathrm{a}$ & $39.1 \mathrm{a}$ & $9.6 \mathrm{a}$ & $1.0 \mathrm{a}$ & $10.6 \mathrm{a}$ & $1.14 \mathrm{a}$ & $1.2 b$ & $2.3 b$ \\
\hline A9P2 & $38.7 \mathrm{a}$ & $0.4 \mathrm{~b}$ & $39.8 \mathrm{a}$ & $10.1 \mathrm{a}$ & $0.7 \mathrm{a}$ & $10.8 \mathrm{a}$ & $1.34 \mathrm{a}$ & $1.8 \mathrm{a}$ & $3.1 \mathrm{a}$ \\
\hline A9XP2 & $15.8 b$ & $0.4 b$ & $38.4 \mathrm{a}$ & $10.8 \mathrm{a}$ & $0.8 \mathrm{a}$ & $11.7 \mathrm{a}$ & $1.08 \mathrm{~b}$ & $1.3 b$ & $2.4 \mathrm{~b}$ \\
\hline A10P5 & $46.6 \mathrm{a}$ & $0.7 \mathrm{a}$ & $38.9 \mathrm{a}$ & $9.4 \mathrm{~b}$ & $0.7 \mathrm{a}$ & $10.1 \mathrm{~b}$ & $0.97 b$ & $1.2 b$ & $2.2 \mathrm{~b}$ \\
\hline A10XP5 & $46.3 \mathrm{a}$ & $0.8 \mathrm{a}$ & $33.6 \mathrm{a}$ & $8.9 \mathrm{~b}$ & $0.9 a$ & $9.9 \mathrm{~b}$ & $1.18 \mathrm{a}$ & $1.4 \mathrm{~b}$ & $2.6 \mathrm{a}$ \\
\hline A11P11 & $50.6 \mathrm{a}$ & $0.5 \mathrm{~b}$ & $43.5 \mathrm{a}$ & $9.0 \mathrm{~b}$ & $0.8 \mathrm{a}$ & $9.9 b$ & $0.88 \mathrm{~b}$ & $1.0 \mathrm{~b}$ & $1.9 \mathrm{~b}$ \\
\hline A11P12 & $41.3 \mathrm{a}$ & $0.7 \mathrm{a}$ & $44.8 \mathrm{a}$ & $9.1 \mathrm{~b}$ & $0.8 a$ & $10.0 \mathrm{~b}$ & $0.91 \mathrm{~b}$ & $1.1 \mathrm{~b}$ & $2.0 \mathrm{~b}$ \\
\hline $\mathrm{A} 11 \mathrm{XP1}$ & $48.0 \mathrm{a}$ & $0.6 \mathrm{a}$ & $38.2 \mathrm{a}$ & $8.6 \mathrm{~b}$ & $0.8 \mathrm{a}$ & $9.4 \mathrm{~b}$ & $1.01 \mathrm{~b}$ & $1.0 \mathrm{~b}$ & $2.1 \mathrm{~b}$ \\
\hline A11XP13 & $35.3 \mathrm{a}$ & $0.7 \mathrm{a}$ & $37.7 \mathrm{a}$ & $10.1 \mathrm{a}$ & $0.8 \mathrm{a}$ & $11.0 \mathrm{a}$ & $1.03 \mathrm{~b}$ & $1.2 \mathrm{~b}$ & $2.2 \mathrm{~b}$ \\
\hline A13XP8 & $38.7 \mathrm{a}$ & $0.4 \mathrm{~b}$ & $45.0 \mathrm{a}$ & $8.5 b$ & $0.7 \mathrm{a}$ & $9.3 b$ & $1.00 \mathrm{~b}$ & $1.0 \mathrm{~b}$ & $2.0 \mathrm{~b}$ \\
\hline A14P2 & $40.7 \mathrm{a}$ & $0.5 \mathrm{~b}$ & $49.1 \mathrm{a}$ & $8.7 \mathrm{~b}$ & $0.7 \mathrm{a}$ & $9.5 b$ & $0.98 b$ & $0.8 \mathrm{~b}$ & $1.8 \mathrm{~b}$ \\
\hline A14P4 & $32.9 \mathrm{a}$ & $0.3 b$ & $43.8 \mathrm{a}$ & $8.1 \mathrm{~b}$ & $0.7 \mathrm{a}$ & $8.8 \mathrm{~b}$ & $0.98 b$ & $1.0 \mathrm{~b}$ & $2.0 \mathrm{~b}$ \\
\hline A16P4 & $25.2 \mathrm{~b}$ & $0.5 \mathrm{~b}$ & $38.5 \mathrm{a}$ & $10.3 a$ & $0.7 \mathrm{a}$ & $11.0 \mathrm{a}$ & $1.41 \mathrm{a}$ & $1.8 \mathrm{a}$ & $3.2 \mathrm{a}$ \\
\hline A18XP4 & $34.9 \mathrm{a}$ & $0.5 \mathrm{~b}$ & $47.3 \mathrm{a}$ & $9.2 \mathrm{~b}$ & $0.8 a$ & $10.0 \mathrm{~b}$ & $0.85 b$ & $0.9 \mathrm{~b}$ & $1.8 \mathrm{~b}$ \\
\hline A19XP2 & $20.7 \mathrm{~b}$ & $0.3 \mathrm{~b}$ & $39.3 \mathrm{a}$ & $9.6 \mathrm{a}$ & $0.7 \mathrm{a}$ & $10.3 \mathrm{a}$ & $1.01 \mathrm{~b}$ & $1.2 \mathrm{~b}$ & $2.2 \mathrm{~b}$ \\
\hline CV(\%) & 50.7 & 45.5 & 26.8 & 17.3 & 22.7 & 16.0 & 28.5 & 51.4 & 31.3 \\
\hline
\end{tabular}

Means followed by the same letter in the column do not differ statistically by the Scott-Knott Test ( $p>0.05)$. SG: seed germination, RDL: radicle length, RL: root length, SL: shoot length, TL: total length, SDW: shoot dry mass, RDW: root dry mass, TDW: total dry mass

Seeds of $D$. insularis had an average in vitro germination reduction of $50.35 \%$, caused by 13 isolates of Pseudomonas spp. (Table 7). Most of these isolates also decreased radicle growth in $D$. insularis seedlings, except for isolates A2P6 and A3P2. Moreover, seven other isolates also decreased radicle growth (Table 7). The germination of $D$. insularis seeds was not decreased by application of Pseudomonas spp. isolates in greenhouse assays (Table 7); however, 22 of the tested isolates decreased root length. Similarly to the previous assays of E. heterophylla with application of Pseudomonas spp., isolates that had no effect on the reduction of seedling growth under laboratory conditions reduced the root length of plants in the greenhouse (Table 7). Eight isolates showed plant growth-promoting effect (DSW and RDW). Of these, isolates $\mathrm{A} 8 \mathrm{P} 2$ and $\mathrm{A} 16 \mathrm{P} 4$ reduced germination and seedling length in the laboratory. Isolates A8P8 and A9P1, in turn, reduced only root length in the laboratory assay, showing that the response to these isolates also appears to be related to the concentration of IAA by having a rate-dependent effect to inhibit germination or promote seedling growth.

Seeds of $C$. sumatrensis were very susceptible to Pseudomonas spp. in the laboratory assay (Table 8). Germination decreased in $75 \%$ of the tested isolates (25 isolates), with an average inhibition of $50.3 \%$. Most of these isolates also decreased seedling radicle length (Table 8 ). On the contrary, in greenhouse assays, germination increased with the application of 18 isolates $(54 \%)$. Fifteen of these isolates inhibited germination or decreased seedling growth in the laboratory (Table 8). Increased wheat germination by DRB isolates was reported by Abbas et al. (2017), in which isolates $\mathrm{T} 19, \mathrm{~L} 9$, and $7 \mathrm{O}_{0}$ significantly increased germination by $14.8,18.5$, and $14.8 \%$ compared to the control, respectively.

Table 8 - Effect of Pseudomonas spp. strains on horseweed (Conyza sumatrensis) control in laboratory and greenhouse conditions.

\begin{tabular}{|c|c|c|c|c|c|c|c|c|c|}
\hline \multirow[b]{2}{*}{ Strains } & \multicolumn{2}{|c|}{ Laboratory experiment } & \multicolumn{7}{|c|}{ Greenhouse experiment } \\
\hline & $\begin{array}{l}S G \\
(\%)\end{array}$ & $\begin{array}{l}\mathrm{RDL} \\
(\mathrm{cm})\end{array}$ & $\begin{array}{l}\text { GS } \\
(\%)\end{array}$ & $\begin{array}{c}\mathrm{RL} \\
(\mathrm{cm})\end{array}$ & $\begin{array}{c}\mathrm{SL} \\
(\mathrm{cm})\end{array}$ & $\begin{array}{c}\mathrm{TL} \\
(\mathrm{cm}) \\
\end{array}$ & $\begin{array}{c}\text { SDW } \\
(\mathrm{g})\end{array}$ & $\begin{array}{c}\text { RDW } \\
\text { (g) }\end{array}$ & $\begin{array}{c}\text { TDW } \\
(\mathrm{g}) \\
\end{array}$ \\
\hline Control & $32.0 \mathrm{a}$ & $0.4 \mathrm{a}$ & $3.7 \mathrm{~b}$ & $5.5 \mathrm{a}$ & $0.2 \mathrm{a}$ & $5.7 \mathrm{a}$ & $0.34 \mathrm{a}$ & $0.3 \mathrm{a}$ & $0.6 \mathrm{a}$ \\
\hline A1P6 & $28.2 \mathrm{~b}$ & $0.3 \mathrm{a}$ & $2.1 \mathrm{~b}$ & $5.8 \mathrm{a}$ & $0.2 \mathrm{a}$ & $6.0 \mathrm{a}$ & $0.40 \mathrm{a}$ & $0.5 \mathrm{a}$ & $0.9 \mathrm{a}$ \\
\hline A1XP10 & $34.6 \mathrm{a}$ & $0.2 \mathrm{a}$ & $5.5 \mathrm{a}$ & $7.4 \mathrm{a}$ & $0.2 \mathrm{a}$ & $7.6 \mathrm{a}$ & $0.35 \mathrm{a}$ & $0.2 \mathrm{a}$ & $0.5 \mathrm{a}$ \\
\hline
\end{tabular}


Cont. Table 8

\begin{tabular}{|c|c|c|c|c|c|c|c|c|c|}
\hline \multirow[b]{2}{*}{ Strains } & \multicolumn{2}{|c|}{ Laboratory experiment } & \multicolumn{7}{|c|}{ Greenhouse experiment } \\
\hline & $\begin{array}{l}S G \\
(\%)\end{array}$ & $\begin{array}{l}\text { RDL } \\
\text { (cm) }\end{array}$ & $\begin{array}{l}\text { GS } \\
(\%)\end{array}$ & $\begin{array}{c}\mathrm{RL} \\
(\mathrm{cm})\end{array}$ & $\begin{array}{c}\mathrm{SL} \\
(\mathrm{cm})\end{array}$ & $\begin{array}{c}\mathrm{TL} \\
(\mathrm{cm})\end{array}$ & $\begin{array}{c}\text { SDW } \\
\text { (g) }\end{array}$ & $\begin{array}{c}\text { RDW } \\
\text { (g) }\end{array}$ & $\begin{array}{c}\text { TDW } \\
\text { (g) }\end{array}$ \\
\hline A2P6 & $8.7 \mathrm{~b}$ & $0.2 \mathrm{~b}$ & $3.4 \mathrm{~b}$ & $5.3 a$ & $0.2 \mathrm{a}$ & $5.6 \mathrm{a}$ & $0.4 \mathrm{a}$ & $0.3 a$ & $0.7 \mathrm{a}$ \\
\hline A2XP3 & $12.0 \mathrm{~b}$ & $0.1 \mathrm{~b}$ & $5.2 \mathrm{a}$ & $6.5 \mathrm{a}$ & $0.2 \mathrm{a}$ & $6.7 \mathrm{a}$ & $0.4 \mathrm{a}$ & $0.3 \mathrm{a}$ & $0.7 \mathrm{a}$ \\
\hline A3P2 & $13.5 \mathrm{~b}$ & $0.1 \mathrm{~b}$ & $2.8 \mathrm{~b}$ & $5.5 \mathrm{a}$ & $0.2 \mathrm{a}$ & $5.7 \mathrm{a}$ & $0.3 a$ & $0.2 \mathrm{a}$ & $0.5 \mathrm{a}$ \\
\hline A3P6 & $8.7 \mathrm{~b}$ & $0.1 \mathrm{~b}$ & $3.2 \mathrm{~b}$ & $5.2 \mathrm{a}$ & $0.3 a$ & $5.5 \mathrm{a}$ & $0.3 a$ & $0.2 \mathrm{a}$ & $0.6 \mathrm{a}$ \\
\hline А3ХP10 & $4.8 \mathrm{~b}$ & $0.1 \mathrm{~b}$ & $3.2 b$ & $5.8 \mathrm{a}$ & $0.2 \mathrm{a}$ & $6.1 \mathrm{a}$ & $0.3 a$ & $0.2 \mathrm{a}$ & $0.5 \mathrm{a}$ \\
\hline A3XP11 & $13.5 b$ & $0.2 \mathrm{a}$ & $3.2 b$ & $5.4 \mathrm{a}$ & $0.2 \mathrm{a}$ & $5.6 \mathrm{a}$ & $0.3 a$ & $0.2 \mathrm{a}$ & $0.6 \mathrm{a}$ \\
\hline A3XP12 & $1.9 \mathrm{~b}$ & $0.2 \mathrm{~b}$ & $2.7 \mathrm{~b}$ & $5.8 \mathrm{a}$ & $0.2 \mathrm{a}$ & $6.0 \mathrm{a}$ & $0.3 a$ & $0.2 \mathrm{a}$ & $0.6 a$ \\
\hline А3ХР14 & $22.6 \mathrm{~b}$ & $0.2 \mathrm{~b}$ & $2.7 \mathrm{~b}$ & $5.6 \mathrm{a}$ & $0.2 \mathrm{a}$ & $6.0 \mathrm{a}$ & $0.2 \mathrm{a}$ & $0.3 \mathrm{a}$ & $0.5 \mathrm{a}$ \\
\hline A3XP15 & $9.7 b$ & $0.1 \mathrm{~b}$ & $3.8 \mathrm{a}$ & $5.2 a$ & $0.2 \mathrm{a}$ & $5.4 \mathrm{a}$ & $0.4 \mathrm{a}$ & $0.2 \mathrm{a}$ & $0.6 \mathrm{a}$ \\
\hline A4XP4 & $26.6 \mathrm{~b}$ & $0.1 \mathrm{~b}$ & $4.4 \mathrm{a}$ & $4.6 \mathrm{a}$ & $0.2 \mathrm{a}$ & $4.8 \mathrm{a}$ & $0.2 \mathrm{a}$ & $0.2 \mathrm{a}$ & $0.4 \mathrm{a}$ \\
\hline A7P1 & $15.5 \mathrm{~b}$ & $0.1 \mathrm{~b}$ & $4.2 \mathrm{a}$ & $5.9 a$ & $0.2 \mathrm{a}$ & $6.1 \mathrm{a}$ & $0.4 \mathrm{a}$ & $0.2 \mathrm{a}$ & $0.6 \mathrm{a}$ \\
\hline A8P2 & $22.5 \mathrm{~b}$ & $0.2 \mathrm{a}$ & $2.7 \mathrm{~b}$ & $5.9 a$ & $0.2 \mathrm{a}$ & $6.2 \mathrm{a}$ & $0.4 \mathrm{a}$ & $0.4 \mathrm{a}$ & $0.9 \mathrm{a}$ \\
\hline A8P4 & $13.3 \mathrm{~b}$ & $0.7 \mathrm{~b}$ & $5.1 \mathrm{a}$ & $6.8 \mathrm{a}$ & $0.2 \mathrm{a}$ & $7.0 \mathrm{a}$ & $0.3 a$ & $0.3 \mathrm{a}$ & $0.7 \mathrm{a}$ \\
\hline A8P8 & $20.7 \mathrm{~b}$ & $0.25 a$ & $2.4 \mathrm{~b}$ & $4.8 \mathrm{a}$ & $0.2 \mathrm{a}$ & $5.0 \mathrm{a}$ & $0.4 \mathrm{a}$ & $0.2 \mathrm{a}$ & $0.6 \mathrm{a}$ \\
\hline A8XP10 & $20.0 \mathrm{~b}$ & $0.09 \mathrm{~b}$ & $5.9 \mathrm{a}$ & $6.7 \mathrm{a}$ & $0.2 \mathrm{a}$ & $6.9 \mathrm{a}$ & $0.4 \mathrm{a}$ & $0.2 \mathrm{a}$ & $0.6 \mathrm{a}$ \\
\hline A8XP9 & $8.7 \mathrm{~b}$ & $0.18 b$ & $4.2 \mathrm{a}$ & $4.8 \mathrm{a}$ & $0.2 \mathrm{a}$ & $5.1 \mathrm{a}$ & $0.4 \mathrm{a}$ & $0.2 \mathrm{a}$ & $0.6 \mathrm{a}$ \\
\hline A9P1 & $19.3 b$ & $0.15 b$ & $5.2 \mathrm{a}$ & $5.0 \mathrm{a}$ & $0.2 \mathrm{a}$ & $5.3 \mathrm{a}$ & $0.4 a$ & $0.2 \mathrm{a}$ & $0.5 \mathrm{a}$ \\
\hline A9P2 & $50.8 \mathrm{a}$ & $0.28 \mathrm{a}$ & $3.0 \mathrm{~b}$ & $4.6 \mathrm{a}$ & $0.2 \mathrm{a}$ & $4.9 \mathrm{a}$ & $0.3 a$ & $0.2 \mathrm{a}$ & $0.6 \mathrm{a}$ \\
\hline A9XP2 & $20.3 \mathrm{~b}$ & $0.24 \mathrm{a}$ & $4.0 \mathrm{a}$ & $5.3 a$ & $0.2 a$ & $5.5 \mathrm{a}$ & $0.4 a$ & $0.2 \mathrm{a}$ & $0.6 \mathrm{a}$ \\
\hline A10P5 & $34.6 \mathrm{a}$ & $0.22 \mathrm{a}$ & $2.9 \mathrm{~b}$ & $5.7 \mathrm{a}$ & $0.2 \mathrm{a}$ & $5.9 \mathrm{a}$ & $0.7 \mathrm{a}$ & $0.6 \mathrm{a}$ & $1.3 \mathrm{a}$ \\
\hline A10XP5 & $11.6 \mathrm{~b}$ & $0.24 \mathrm{a}$ & $4.4 \mathrm{a}$ & $5.4 \mathrm{a}$ & $0.3 a$ & $5.7 \mathrm{a}$ & $0.4 \mathrm{a}$ & $0.2 \mathrm{a}$ & $0.6 \mathrm{a}$ \\
\hline A11P11 & $40.0 \mathrm{a}$ & $0.12 b$ & $2.6 \mathrm{~b}$ & $6.4 \mathrm{a}$ & $0.2 \mathrm{a}$ & $6.6 \mathrm{a}$ & $0.3 a$ & $0.5 \mathrm{a}$ & $0.8 \mathrm{a}$ \\
\hline $\mathrm{A} 11 \mathrm{P} 12$ & $22.6 \mathrm{~b}$ & $0.21 \mathrm{~b}$ & $4.4 \mathrm{a}$ & $6.9 \mathrm{a}$ & $0.2 \mathrm{a}$ & $7.2 \mathrm{a}$ & $0.4 a$ & $0.3 a$ & $0.7 \mathrm{a}$ \\
\hline A11XP1 & $37.3 \mathrm{a}$ & $0.30 \mathrm{a}$ & $3.0 \mathrm{~b}$ & $6.0 \mathrm{a}$ & $0.2 a$ & $6.2 \mathrm{a}$ & $0.3 a$ & $0.4 \mathrm{a}$ & $0.7 \mathrm{a}$ \\
\hline $\mathrm{A} 11 \times \mathrm{P} 13$ & $18.4 \mathrm{~b}$ & $0.28 \mathrm{a}$ & $4.0 \mathrm{a}$ & $6.7 \mathrm{a}$ & $0.2 \mathrm{a}$ & $7.0 \mathrm{a}$ & $0.3 a$ & $0.2 \mathrm{a}$ & $0.5 \mathrm{a}$ \\
\hline A13XP8 & $16.0 \mathrm{~b}$ & $0.15 b$ & $6.3 \mathrm{a}$ & $7.0 \mathrm{a}$ & $0.2 \mathrm{a}$ & $7.3 \mathrm{a}$ & $0.3 a$ & $0.2 \mathrm{a}$ & $0.5 a$ \\
\hline A14P2 & $36.0 \mathrm{a}$ & $0.17 b$ & $4.3 \mathrm{a}$ & $7.0 \mathrm{a}$ & $0.2 \mathrm{a}$ & $7.2 \mathrm{a}$ & $0.3 a$ & $0.3 a$ & $0.6 \mathrm{a}$ \\
\hline A14P4 & $14.6 \mathrm{~b}$ & $0.09 \mathrm{~b}$ & $2.0 \mathrm{~b}$ & $6.0 \mathrm{a}$ & $0.2 \mathrm{a}$ & $6.3 \mathrm{a}$ & $0.3 a$ & $0.4 \mathrm{a}$ & $0.9 a$ \\
\hline A16P4 & $33.8 \mathrm{a}$ & $0.30 \mathrm{a}$ & $5.0 \mathrm{a}$ & $8.0 \mathrm{a}$ & $0.2 \mathrm{a}$ & $8.3 \mathrm{a}$ & $0.4 \mathrm{a}$ & $0.3 a$ & $0.7 \mathrm{a}$ \\
\hline A18XP4 & $24.0 \mathrm{~b}$ & $0.13 b$ & $4.6 \mathrm{a}$ & $5.4 \mathrm{a}$ & $0.2 \mathrm{a}$ & $5.6 \mathrm{a}$ & $0.3 a$ & $0.3 \mathrm{a}$ & $0.6 \mathrm{a}$ \\
\hline A19XP2 & $63.5 \mathrm{a}$ & $0.38 \mathrm{a}$ & $4.3 \mathrm{a}$ & $5.3 a$ & $0.3 a$ & $5.6 \mathrm{a}$ & $0.4 \mathrm{a}$ & $0.2 \mathrm{a}$ & $0.5 \mathrm{a}$ \\
\hline CV (\%) & 102.2 & 67.3 & 44.2 & 26.4 & 17.0 & 25.1 & 44.4 & 61.5 & 47.7 \\
\hline
\end{tabular}

Means followed by the same letter in the column do not differ statistically by the Scott-Knott Test $(p>0.05)$. SG:seed germination, RDL: radicle length, RL: root length, SL: shoot length, TL: total length, SDW: shoot dry mass, RDW: root dry mass, TDW: total dry mass

For the three weed species studied, radicle growth seems to be more affected by bacterial application than germination under both in vitro and greenhouse conditions. The same can be observed in the study of Kennedy et al. (2001) with $P$. fluorescens D7 supernatant on various weed species. Of the 26 plant species evaluated in Petri dishes with agar-water, 19 inhibited root growth, while only 10 showed inhibition of germination.

We can infer from this study that the mass selection of rhizobacteria for pre-emergence control of weeds by the in vitro methodology tested may not be the most adequate for the selection of isolates. Most of the time, the efficiency of some in vitro isolates was not corroborated by greenhouse experiments. Similar results were found by Kennedy et al. (2001) using isolate Pseudomonas fluorescens D7. In their study, no correlation was found between the bioassay with plate supernatants and the responses found in the soil bioassay $\left(R^{2}=0.18\right)$, since root inhibition was always higher in agar-water than in soil. The authors attributed this effect to the ability of competition and colonization of the rhizosphere by bacteria in soil compared to agarwater medium. 
Inhibition of seed germination is the main and most sought-after effect of DRBs for biological control of weeds due to the ability to reduce plant population in the field (seed bank). Considering the inhibition of seed germination, we conclude that Bacillus spp. isolates A1B1, A1B3, A1B4, A2B2, A2B3, A10B1, A10B5, $A 11 B 1$, and $A 13 B 3$ were able to effectively inhibit the germination of $C$. sumatrensis seeds under greenhouse conditions. These isolates are promising and should be identified at the species level and characterized for metabolite production, plant growth regulation, root colonization, and effect on cultivated plants.

\section{Acknowledgements}

To the Professional Masters Course in Plant Production of IFTM-Uberaba for granting financial support to the research, and to the "ad hoc" rapporteurs of this article for the valuable suggestions and corrections.

\section{References}

Abbas T, Zahir Z A, Naveed M (2017) Bioherbicidal activity of allelopathic bacteria against weeds associated with wheat and their effects on growth of wheat under axenic conditions. BioControl 62:719-730.

Alfenas AC, Mafia RG (2007) Métodos em Fitopatologia. Viçosa: UFV. 382p.

Åström B, Gerhardson B (1988) Diferential reactions of wheat and pea genotypes to root inoculation with growth-afecting rhizosphere bacteria. Plant Soil (109):269-263.

Barroso AMB, Toledo RE Resistência Planta Daninhas I (2014) Disponível em < http://www.hracbr.com.br/wordpress/wp-

content/uploads/2014/08/poster-1.pdf> Acesso em 10 abr. 2016.

Barroso AMB, Toledo RE Resistência Planta Daninhas II (2014) Disponível em < http://www.hracbr.com.br/wordpress/wp-

content/uploads/2014/08/poster-2.pdf> Acesso em 10 abr. 2016.

Barroso AMB, Toledo, RE Resistência Planta Daninhas III (2014) Disponível em < http://www.hracbr.com.br/wordpress/wp-

content/uploads/2014/08/poster-3.pdf> Acesso em 10 abr. 2016.

Begonia MFT, Kremer RJ, Begonia GB (1998) Biological control of weeds: Effects of rhizobacterial inoculation on the growth of velvetleaf (Abutilon theophrasti Medik.). Journal of the Mississippi Academy of Sciences (43):117-107.

Carvalho DDC, Oliveira DF, Campos VP, Pasqual M (2011) Selection of phytotoxin producing rhizobacteria. Anais da Academia Brasileira de Ciências (83): 3, 1096-1091.
Chauhan LS, Tomar YK, Singh NI, Ali S (2009) Effect of growth hormones on seed germination and seedling growth of black gram and horse gram. Journal of American Science 5 (5): 79-84.

Christoffoleti PJ, Nicolai M (2016) Aspectos de resistência de plantas daninhas a herbicidas. 4th. ed. Piracicaba: Esalg. 262p.

Duke SO, Powles SB (2008) Glyphosate: a once in a century herbicide. Pest Management Science (64): 4: 325-319.

Flores-Vargas RD, O'Hara GW (2006) Isolation and characterization of rhizosphere bacteria with potential for biological control of weeds in vineyards. Journal of Applied Microbiology (100): 954-946.

Ju C, Chang C (2015) Mechanistic insights in ethylene perception and signal transduction. Plant Physiology (169): 85-95.

Katzer W, Charman K, Blackburn M, Martin SM (2001) Scale-up of filamentous organisms from tubes and shake-flasks into stirred vessels. Biochemical Engineering Journal (7), 2,134-127.

Kennedy AC, Johnson BN, Stubbs TL (2001) Host range of a deleterious rhizobacterium for biological control of downy brome. Weed Science (49): 797-792.

King EO, Ward M, Raney DEJJ. Laboratório de Clínica Médica, 1954, 44, p. 301.

Lin L, Li Z, Hu C, Zhang X, Chang S, Yang L, Li Y, An $Q$ (2012) Plant growth promoting nitrogen fixing enterobacteria are in association with sugarcane plants growing in Guangxi, China. Microbes and Environments (27): 391-398.

Li J, Kremer RJ (2006) Growth response of weed and crop seedlings to deleterious rhizobacteria. Biological Control (39): 65-58.

Li Y, Sun Z, Zhuang X, Xu L, Chen S, Li M (2003) Research progress on microbial herbicides. Crop Protection (22): 252-247.

Mondo VHV, Carvalho SJP, Dias, ACR, Marco Filho J (2010) Efeitos da luz e temperatura na germinação de sementes de quatro espécies de plantas daninhas do gênero Digitaria. Revista Brasileira Sementes (32): 1:137-131.

Nandula VK, Eubank TW, Poston DH, Koger $\mathrm{CH}$, Reddy KN (2006) Factors affecting germination of horseweed (Conyza canadensis). Weedy Science (54): 5: 902-898.

Oliveira JR RS, Constantin J, Inoue MH (2011) Biologia e Manejo de Plantas Daninhas. Curitiba, PR: Omnipax. 348 p.

Patil VS (2014) Isoaltion, characterization and identification of rhizospheric bacteria with the potential for biological control of Sida acuta. Journal of Environmental Research and Development (8): 411417 
Prigol A, Galon L, Forte CT, Kujawiski R, Concenço G, Trezzi MM, Trevisol R, Radünz AL, Perin GF (2014) Avaliação de biótipos de leiteiro com suspeita de resistência a herbicidas inibidores da ALS e Protox. Revista Brasileira de Herbicidas (13): 3: 216-224.

Santos G, Oliveira Jr. RS, Constantin J, Francischini AC, Osipe JB (2014) Multiple resistance of Conyza sumatrensis to chlorimuronethyl and to glyphosate. Planta Daninha v. 32, n. 2, 409-416.

Suda CNK, Pereira MFDA (1997) Sensibilidade à luz de sementes de Euphorbia heterophylla L. durante a germinação. Revista Brasileira de Fisiologia Vegetal (9): 1: 1-66.

Tabatabaei S, Ehsanzadeh $\mathrm{P}$, Etesami $\mathrm{H}$, Alikhani HA, Glick BR (2016) Indole-3-acetic acid (IAA) producing Pseudomonas isolates inhibit seed germination and a-amylase activity in durum wheat (Triticum turgidum L.). Spanish Journal of Agricultural Research (14):1: e0802.
Trezzi MM, Vidal RA, Kruse ND, Nunes AL. (2006) Bioensaios para identificação de biótipos de Euphorbia heterophylla com resistência múltipla a inibidores da ALS e da PROTOX. Planta Daninha v. 24, n. 3, 563571.

Tuite J (1969) Plant pathological methods. Minneapolis: Burguess. $239 \mathrm{p}$.

World Organization (1985) Informal consultation on the development of Bacillus sphaericus as microbial larvicide. Geneva: UNDP/World Bank/WHO Special programmer of research and training in tropical diseases, $24 p$.

Zhang Q, Xiu Z (2009) Metabolic pathway analysis of glycerol metabolism in Klebsiella pneumoniae incorporating oxygen regulatory system. Biotechnology Progress (25): 15-103. 